ENVIRONMENTAL

RESTORATION

PROGRAM

\section{Confirmatory Sampling and Analysis Plan for the Lower East Fork Poplar Creek Operable Unit, Oak Ridge, Tennessee}

This document has been approved for release to the public by the Y-12 Plant Techncial Information Office. Date:

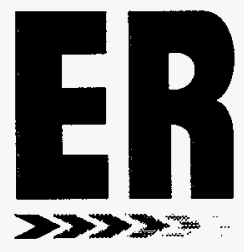




\section{Science Applications International Corporation}

contributed to the preparation of this document and should not be considered an eligible contractor for its review.

This report has been reproduced directly from the best available copy.

Available to DOE and DOE contractors from the Office of Scientific and Technical Information, P.O. Box 62, Oak Ridge, TN 37831; prices available from 423-576-8401 (fax 423-576-2865).

Available to the public from the National Technical Information Service, U.S. Department of Commerce, 5285 Port Royal Rd., Springfield, VA 22161. 
Energy Systems Environmental Restoration Program

\section{Confirmatory Sampling and Analysis \\ Plan for the Lower East Fork Poplar Creek Operable Unit, Oak Ridge, Tennessee}

Date Issued-April 1996

Prepared by

Science Applications International Corporation Oak Ridge, Tennessee under subcontract 43B-99069C, Y05

Prepared for the

U.S. Department of Energy Office of Environmental Management under budget and reporting code EW 20

Environmental Management Activities at the

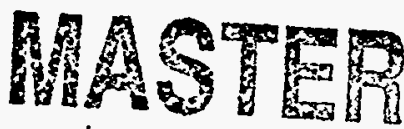
OAK RIDGE Y-12 PLANT

Oak Ridge, Tennessee 37831-8169

managed by

LOCKHEED MARTIN ENERGY SYSTEMS, INC.

for the

U.S. DEPARTMENT OF ENERGY

under contract DE-AC05-84OR21400 
- 


\section{DISCLAIMER}

Portions of this document may be illegible in electronic image products. Images are produced from the best available original document. 


\section{DISCLAIMER}

This report was prepared as an account of work sponsored by an agency of the United States Government. Neither the United States Government nor any agency thereof, nor any of their employees, makes any warranty, express or implied, or assumes any legal liability or responsibility for the accuracy, completeness, or usefulness of any information, apparatus, product, or process disclosed, or represents that its use would not infringe privately owned rights. Reference herein to any specific commercial product, process, or service by trade name, trademark, manufacturer, or otherwise does not necessarily constitute or imply its endorsement, recommendation, or favoring by the United States Government or any agency thereof. The views and opinions of authors expressed herein do not necessarily state or reflect those of the United States Government or any agency thereof. 


\section{PREFACE}

This Confirmatory Sampling and Analysis Plan for the Lower East Fork Poplar Creek Operable Unit, Oak Ridge, Tennessee (Y/ER-258) was prepared in accordance with requirements under the Comprehensive Environmental Response, Compensation, and Liability Act of 1980 (CERCLA) to present the plan for Confirmation Sampling and Analysis as part of the selected remedy. This work was performed under Work Breakdown Structure 1.4.12.3.1.04, Activity Data Sheet 9304 "Lower East Fork Poplar Creek." This document provides the Environmental Restoration Program with information about the methodology and organizational structure that will be used to confirm the success of the remedial action. 


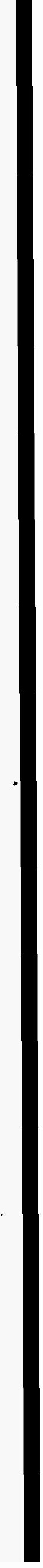




\section{CONTENTS}

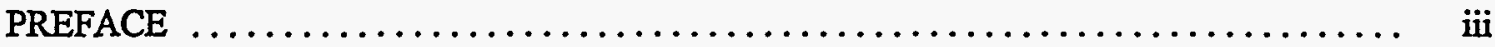

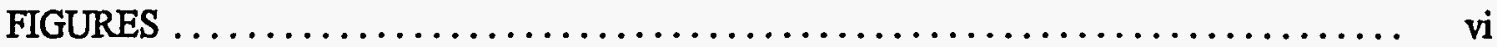

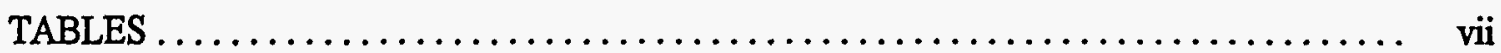

ABBREVIATIONS $\ldots \ldots \ldots \ldots \ldots \ldots \ldots \ldots \ldots \ldots \ldots \ldots \ldots \ldots \ldots \ldots \ldots \ldots \ldots \ldots \ldots \ldots$

EXECUTIVE SUMMARY $\ldots \ldots \ldots \ldots \ldots \ldots \ldots \ldots \ldots \ldots \ldots \ldots \ldots \ldots \ldots \ldots \ldots \ldots \ldots$

1. FIELD SAMPLING AND ANALYSIS PLAN $\ldots \ldots \ldots \ldots \ldots \ldots \ldots \ldots \ldots \ldots \ldots \ldots$

1.1 INTRODUCTION ....................................

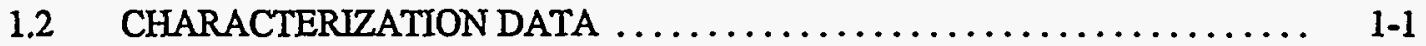

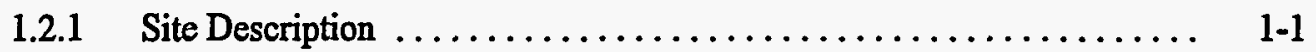

1.2.2 Source of Contamination $\ldots \ldots \ldots \ldots \ldots \ldots \ldots \ldots \ldots \ldots \ldots, 1-2$

1.2.3 Nature and Extent of Contamination $\ldots \ldots \ldots \ldots \ldots \ldots \ldots \ldots \ldots, 1-2$

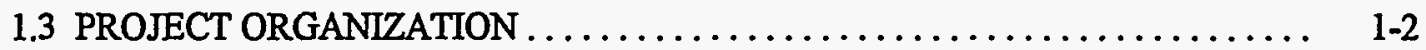

1.3.1 Responsibilities and Coordination of Sampling Activities ......... 1-6

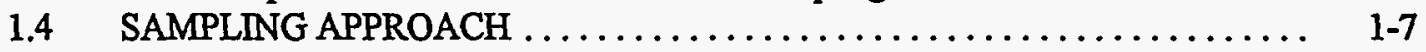

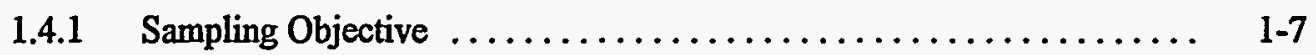

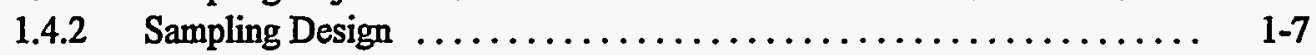

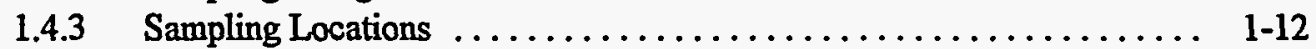

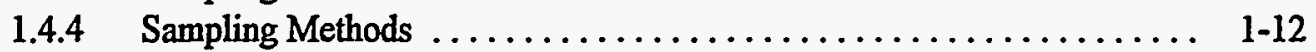

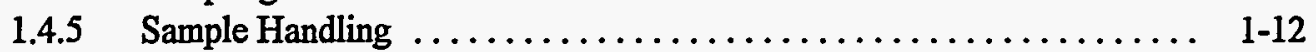

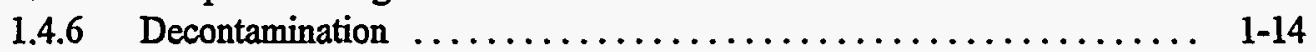

2. QUALITY ASSURANCE PROJECT PLAN $\ldots \ldots \ldots \ldots \ldots \ldots \ldots \ldots \ldots \ldots \ldots \ldots \ldots \ldots \ldots \ldots \ldots$

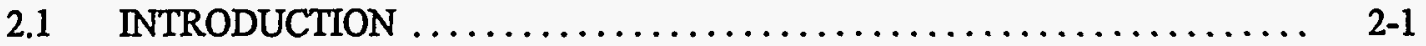

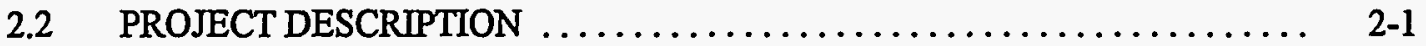

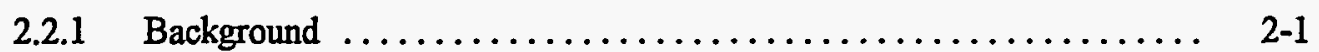

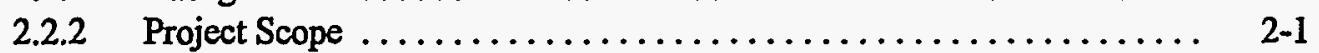

2.3 PROJECT ORGANIZATION AND RESPONSIBILITIES $\ldots \ldots \ldots \ldots \ldots \ldots .2-1$

2.4 READINESS REVIEW ............................... 2-1

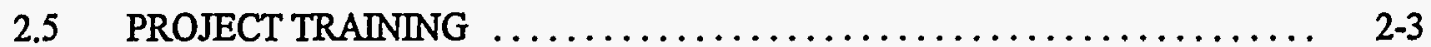

2.6 QA OBJECTIVES FOR DATA MEASUREMENT $\ldots \ldots \ldots \ldots \ldots \ldots \ldots \ldots .2-3$

2.6.1 Intended Uses of Acquired Data .................... 2-3

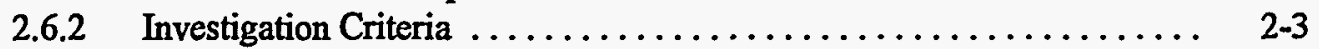

2.7 FIELD ACTIVITY PROCEDURES $\ldots \ldots \ldots \ldots \ldots \ldots \ldots \ldots \ldots \ldots \ldots, 2-4$

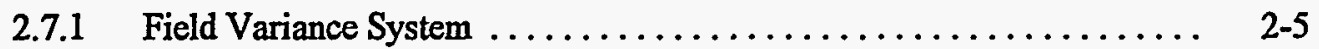

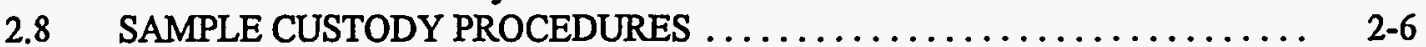

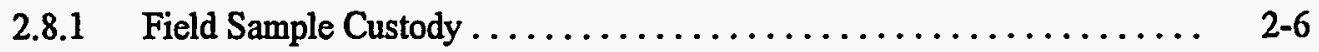

2.8.2 Laboratory Sample Custody ....................... 2-6

2.9 CALIBRATION PROCEDURES AND FREQUENCY $\ldots \ldots \ldots \ldots \ldots \ldots \ldots . . \ldots . \ldots . \ldots$

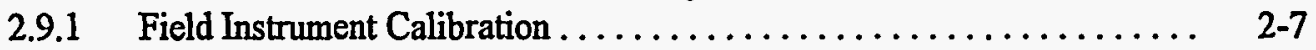

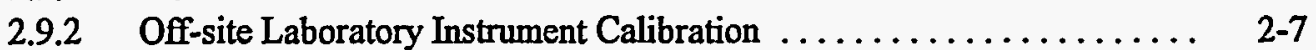




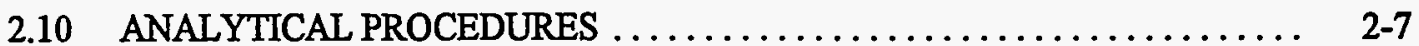

2.11 DATA REDUCTION, VERIFICATION, VALIDATION,

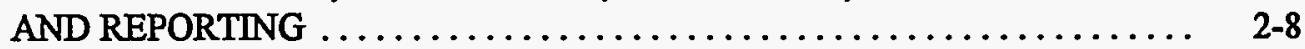

2.11.1 Data Reduction and Verification $\ldots \ldots \ldots \ldots \ldots \ldots \ldots \ldots \ldots . . \ldots \ldots$

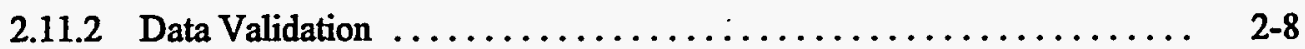

2.11.3 Data Validation Criteria .......................... 2-9

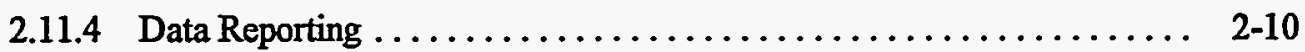

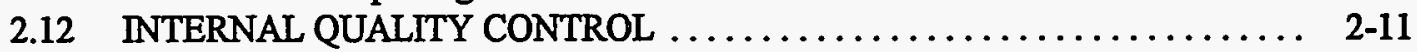

2.12.1 Field Quality Control Samples ...................... 2-11

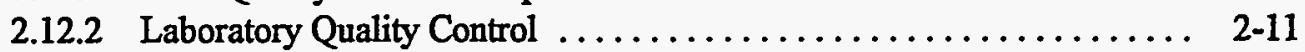

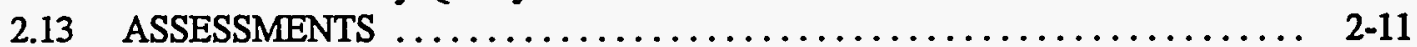

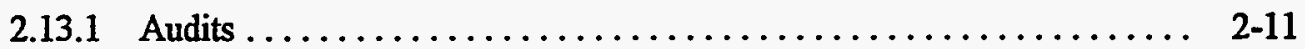

2.13.2 Surveillances $\ldots \ldots \ldots \ldots \ldots \ldots \ldots \ldots \ldots \ldots \ldots \ldots \ldots \ldots, 2-11$

2.13.3 Project Data Quality Assessment .................. 2-12

2.14 PREVENTIVE MAINTENANCE PROCEDURES AND SCHEDULES . . . . . 2-14

2.14.1 Sampling and Screening Equipment $\ldots \ldots \ldots \ldots \ldots \ldots \ldots \ldots \ldots$ 2-14

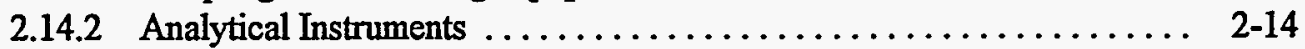

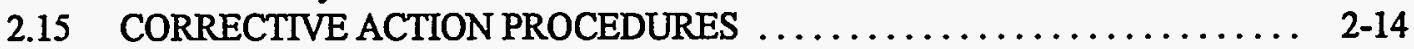

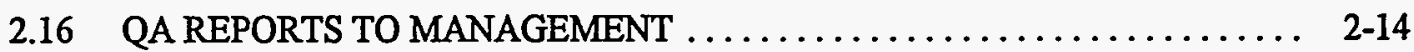

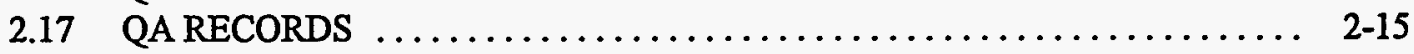

3. SAIC SITE AND TASK SPECIFIC HEALTH AND SAFETY PLAN FOR

CONFIRMATORY SOIL SAMPLING $\ldots \ldots \ldots \ldots \ldots \ldots \ldots \ldots \ldots \ldots \ldots \ldots$ 3-1

3.1 SITE HEALTH AND SAFETY PERSONNEL $\ldots \ldots \ldots \ldots \ldots \ldots \ldots \ldots \ldots$

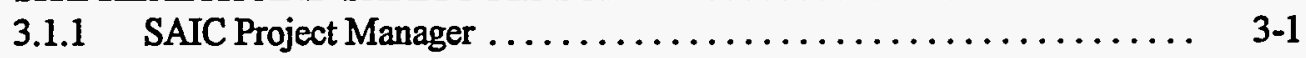

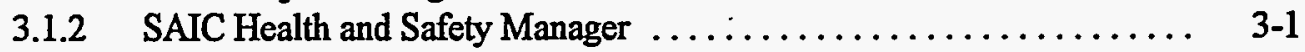

3.1.3 Field Project Personnel ......................... 3-1

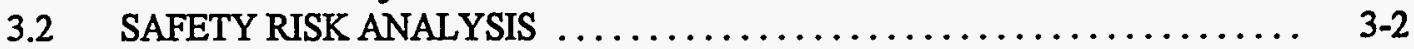

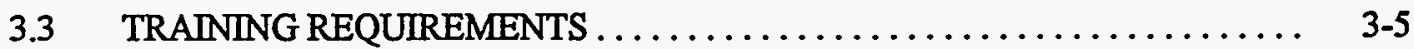

3.4 PERSONAL PROTECTIVE EQUIPMENT $\ldots \ldots \ldots \ldots \ldots \ldots \ldots \ldots \ldots \ldots . \ldots \ldots$

3.5 MEDICAL SURVEILLANCE ........................... 3-6

3.6 MONITORING AND SAMPLING $\ldots \ldots \ldots \ldots \ldots \ldots \ldots \ldots \ldots \ldots \ldots \ldots \ldots \ldots \ldots$

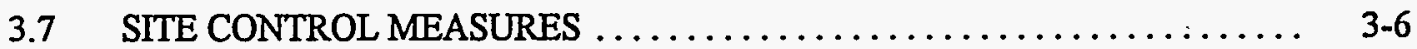

3.8 DECONTAMINATION PROCEDURES $\ldots \ldots \ldots \ldots \ldots \ldots \ldots \ldots \ldots \ldots, 3.7$

3.9 SITE OPERATING PROCEDURES $\ldots \ldots \ldots \ldots \ldots \ldots \ldots \ldots \ldots \ldots \ldots \ldots, \quad 3-7$

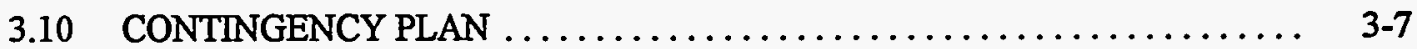

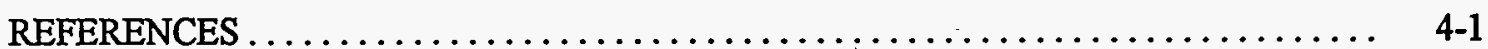




\section{FIGURES}

1.1 East Fork Poplar Creek NOAA Site, Oak Ridge, Tennessee. ............... 1-3

1.2 East Fork Poplar Creek Bruner Site, Oak Ridge, Tennessee $\ldots \ldots \ldots \ldots \ldots \ldots \ldots \ldots$ 1-4

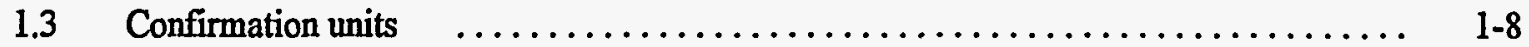

\section{TABLES}

1.1 Roles and responsibilities of the sampling team $\ldots \ldots \ldots \ldots \ldots \ldots \ldots \ldots \ldots \ldots \ldots$

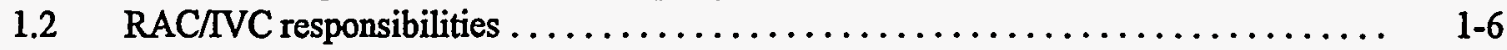

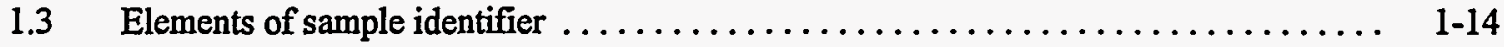

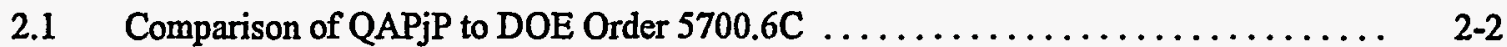

2.2 Field Procedures for the EFPC remediation confirmation analysis ............. $2-5$

2.3 Data set deliverables for summary and comprehensive documentation $\ldots \ldots \ldots \ldots \ldots$ 2-10

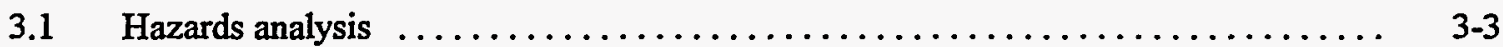

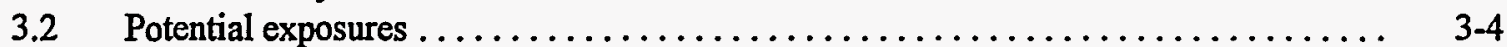

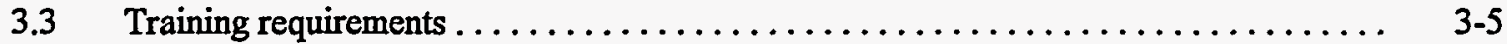





\section{ABBREVIATIONS}

$\% \mathrm{R}$

CERCLA

CLP

$\mathrm{CRF}$

CUs

DOE

DOE-OR

DOT

ECU

EFPC

EPA

ER

ESAMS

FCO

FFA

FP

GI

GPS

HASP

ICP

IDLH

IP

IVC

JEG

LCS

LMES

MS

NA

NCR

NIOSH

NOAA

NPL

ORAU

ORNL

ORR

OSHA

OU

PARCC

PCU

PEL

PPE

ppm

QA/QC

QAPjP

RAC percent recovery

Comprehensive Environmental Response, Compensation, and Liability Act (EPA) Contract Laboratory Procedure

Central Records Facility

confirmation units

U.S. Department of Energy

DOE Field Office in Oak Ridge

U.S. Department of Transportation

Excavation Confirmation Unit

East Fork Poplar Creek

U.S. Environmental Protection Agency

Environmental Restoration

Energy Systems Action Management System

field change order

Federal Facilities Agreement

flash point

gastrointestinal tract

Global Positioning System

Health and Safety Plan

inductively coupled plasma

immediately dangerous to life and health

ionization potential

Independent Verification Contractor

Jacobs Engineering Group

laboratory control sample

Lockheed Martin Energy Systems, Inc.

matrix spike

not available

nonconformance report

National Institute for Occupational Safety and Health

National Oceanic and Atmospheric Administration

National Priorities List

Oak Ridge Associated Universities

Oak Ridge National Laboratory

Oak Ridge Reservation

Occupational Safety and Health Administration

operable unit

precision, accuracy, representativeness, completeness, and comparability

Perimeter Confirmation Unit

permissible exposure limit

personal protective equipment

parts per million

quality assurance/quality control

Quality Assurance Project Plan

Remedial Action Contractor 
RAR

RPD

SAIC

SAP

SHSO

SRM

TBD

TDEC

TLV

TWA

VP

WMP
Remedial Action Report

relative percent difference

Science Applications International Corporation

Sampling and Analysis Plan

Site Health and Safety Officer

standard reference material

to be determined

Tennessee Department of Environment and Conservation

threshold limit value

time-weighted average

vapor pressure

Waste Management Plan 


\section{EXECUTIVE SUMMARY}

\section{SITE BACKGROUND}

On December 21, 1989, the U.S. Environmental Protection Agency (EPA) placed the U.S. Department of Energy's (DOE's) Oak Ridge Reservation (ORR) on the National Priorities List (NPL). On January 1, 1992, a Federal Facilities Agreement (FFA) between the DOE Field Office in Oak Ridge (DOE-OR), EPA Region IV, and the Tennessee Department of Environment and Conservation (TDEC) went into effect. The Lower East Fork Poplar Creek (EFPC) site is designated as an ORR operable unit (OU) under the Comprehensive Environmental Response, Compensation, and Liability Act (CERCLA) and is included on the NPL. Both the EFPC and its floodplain have been contaminated by releases from the Y-12 Plant since the mid-1950s.

The EFPC remediation must follow the specific procedures mandated by CERCLA, as amended by the Superfund Amendments and Reauthorization Act in 1986. In accordance with CERCLA, a feasibility study was prepared to assess remedial alternatives and a proposed plan identifying the preferred alternative was issued. The proposed plan was modified in response to public input and a Record of Decision was issued in 1995 committing to excavation of all soil in the EFPC floodplain where the mercury concentration exceeds 400 parts per million (ppm).

\section{OBJECTIVE}

The document presented here, The Confirmatory Sampling and Analysis Plan (SAP) for the Lower EFPC, describes the organization, strategy, and procedures to be used to confirm that mercury concentrations in soils in the remediated areas are statistically less than, or equal to, the cleanup standard of $400 \mathrm{ppm}$. It focuses on confirming the cleanup of the stretch of the EFPC flowing from Lake Reality at the Y-12 Plant, through the City of Oak Ridge, to Poplar Creek on the ORR and its associated floodplain.

\section{CHAIN OF AUTHORITY}

The EFPC remedial action is being conducted for DOE-OR as part of the Environmental Restoration Program by Lockheed Martin Energy Systems, Inc. (LMES). For the purposes of this remedial action, LMES is also the Remedial Action Contractor (RAC). MK-Ferguson, a subcontractor to LMES, will be responsible for the construction activities. Science Applications International Corporation (SAIC) will provide confirmation sampling services as an LMES subcontractor reporting to MK-Ferguson. The Jacobs Engineering Group (JEG) will be the Independent Verification Contractor (IVC), who independently verifies that the cleanup has met the cleanup standard and reports the results directly to DOE-OR. The EPA and TDEC have review and approval authority as provided in the FFA. 


\section{SCHEDULE}

The remedial action will occur in two phases. Phase I will occur at the National Oceanographic and Atmospheric Administration facility during the spring of 1996 followed by the full scale remediation (Phase II) beginning in the spring of 1997.

\section{RAC Responsibilities}

The RAC will collect sufficient samples to document the success of the cleanup, establish the locations for confirmatory sampling, collect 2- to 8-in. deep screening samples to help direct the excavation, collect 16-in. deep samples to confirm the cleanup using an on-site analytical laboratory ( $10 \%$ will be sent to an off-site laboratory for QA/QC purposes), and report the confirmation results to DOE. A 3- to 7-d turnaround will be requested for all off-site analyses. Each confirmation sample will be archived for $28 \mathrm{~d}$ in plastic or glass containers.

The on-site analytical laboratory will use the Static Headspace Analysis for Mercury in Soils (Kriger and Turner 1996, in press). Off-site laboratory analyses will be performed using CLP ILM3.0 protocols for mercury analysis by cold vapor atomic absorption spectroscopy.

\section{IVC Responsibilities}

The IVC may conduct two types of verification procedures at a site.

Type A verifications include the review of the RAC remedial action plan, release criteria, procedures, final survey documentation and final project documentation, and if appropriate, analysis of split samples. The IVC may also recommend corrective actions for discrepancies.

Type B verifications include on-site visit(s) and survey(s) involving sampling and/or split sample analyses, as necessary, in addition to all other Type A activities. It is anticipated that the IVC will require $\sim 10 \%$ of the samples to be split. All IVC laboratory analyses will be performed off site using CLP ILM3.0 protocols for mercury analysis by cold vapor atomic absorption spectroscopy. A 3- to 7-d turnaround will be requested for all off-site analyses.

The IVC expects to conduct Type B surveys, but reserves the right to revert to Type A after it has been established that the RAC confirmation process is being properly conducted.

\section{Formal Confirmation Documentation Procedure}

The RAC will collect sufficient samples to fully confirm cleanup and submit documentation to DOE. The IVC verifies that cleanup has met standards and reports the results to DOE. DOE issues a Remedial Action Report (RAR) containing confirmation and verification documentation certifying the site has attained the cleanup criteria. The EPA and TDEC review and approve the RAR in accordance with the requirements of the FFA.

\section{Release Documentation for Remedial Action Demobilizations}

After portions of the site are remediated (including Phase I), but months prior to the issuance of the RAR, the RAC must demobilize from one area and move to another. When demobilization and remobilization are required, a data summary with validated results will be transmitted by the 
RAC to DOE in the form of a letter report. DOE will then approve the cleanup based on IVC verification of results. Rapid feedback and approval will be required by EPA and TDEC.

\section{METHODOLOGY}

The U.S. Environmental Protection Agency's (EPA's) Methods for Evaluating the Attainment of Cleanup Standards, Volume 1: Soils and Solid Media, EPA 230/02-89-042, February, 1989, will be used as the methodology for determining the success of the cleanup.

\section{Sampling Frequency and Parameters}

Confirmation units (CUs) of $232 \mathrm{~m}^{2}\left(2500 \mathrm{ft}^{2}\right)$ are recommended for this site based on the total area to be remediated, the pattern of mercury distribution, and the remediation schedule. Typically, contiguous areas where the mercury concentration exceeds $400 \mathrm{ppm}$ are several to tens of multiples of the CU size. The smallest areas to be remediated range from 140 to $325 \mathrm{~m}^{2}$ (1500 to $3500 \mathrm{ft}^{2}$ ). It is anticipated that 153 to $229 \mathrm{~m}^{3}$ (200 to $\left.300 \mathrm{yd}^{3}\right)$ of soil will be excavated on a daily basis. The average excavation depth will be approximately $41 \mathrm{~cm}(16 \mathrm{in})$. Therefore, the area to be excavated on a daily basis will range between 372 to $557 \mathrm{~m}^{2}$ (4000 to $\left.6000 \mathrm{ft}^{2}\right)$. A CU size of $232 \mathrm{~m}^{2}\left(2500 \mathrm{ft}^{2}\right)$ will permit 1 to 2 CUs to be verified daily, allowing the RAC to respond quickly to stormflow and other time critical conditions, thereby reducing the impact of such conditions on the remedial action schedule.

Two types of confirmation units will be used: Perimeter Confirmation Units (PCUs) and Excavation Confirmation Units (ECUs). PCUs will be established by the IVC prior to excavation and will be used to bound the areas of the excavation. They will extend $3 \mathrm{~m}(10 \mathrm{ft})$ outward from the areas to be excavated and have been sampled sufficiently so as to determine them to be clean using the EPA methodology referenced above. ECUs will be established on the floor of the excavation and samples will be drawn from them to confirm the cleanup using the same methodology.

The number of samples required under the EPA methodology varies based on the false positive $(\alpha)$ and false negative $(\beta)$ error rates deemed acceptable for the project. A false positive error rate is the probability that a $\mathrm{CU}$ is incorrectly declared clean. A false negative error rate is the converse. That is, the CU is incorrectly declared to be above the cleanup standard. For this project, an $\alpha$ of 0.01 has been chosen, which implies that there is a 1 chance in 100 that an ECU may be incorrectly declared clean. The false negative rate $(\beta)$ is less critical from a health and safety standpoint, and therefore it has been set to 0.1 , which implies there is a 1 in 10 chance that a clean ECU will be declared dirty.

The actual number of samples required from each CU depends not only on the acceptable error rates, but on the mean and standard deviation of the CU sample population. Because the PCUs are established in areas that will not be excavated it is probable that they will have higher mean mercury concentrations and higher standard deviations than the adjacent ECUs where the mercury will be completely removed. Therefore, the number of samples required to demonstrate that the PCUs are clean will be larger than the number required to confirm the cleanup of the ECUs. For that reason, the sample number requirements were developed based on PCU population estimates. Actual characterization data taken from the clean areas were used to estimate the sample number for both 
PCUs and ECUs. Based on the EPA methodology, it was determined that four samples will be required to be randomly selected from each PCU or ECU.

The "Null and Alternative Hypotheses" are the statistically defensible tools used to determine whether a CU has met the cleanup criteria based on the mean of the samples. These hypotheses compare the true mean of the samples with the cleanup standard.

The beginning assumption (the Null hypothesis) is that the areas defined by the pre-remedial action characterization activities are contaminated. To be considered clean, samples must demonstrate in a statistically defensible manner that the $\mathrm{CU}$ is clean. This is the Alternative hypothesis. For this remedial action, the site will be shown to be clean at the $95 \%$ confidence level.

\section{Quality Assurance Project Plan}

The quality assurance project plan included in this document was prepared in accordance with DOE Order 5700.6C and includes the following elements: project description, organization and responsibilities, requirements for a readiness review, functional activities, and specific protocols that will be followed for sampling, chain of custody, calibration, laboratory analysis, data reduction, verification/validation, and data reporting.

\section{Site and Task Specific Health and Safety Plan for Confirmatory Soil Sampling}

The Health and Safety Plan for this SAP outlines the responsibilities of the SAIC sampling team in performance of the confirmatory sampling activity. It also includes full compliance with the MKFerguson Site Health and Safety Plan. It includes identification of the SAIC Project and Health and Safety Managers, requirements for field project personnel, a safety risk analysis, identification of training requirements, use of personal protective equipment, medical surveillance requirements, monitoring and sampling requirements, site control measures, decontamination procedures, site operating procedures, and requirements for a contingency plan. 


\section{FIELD SAMPLING AND ANALYSIS PLAN}

\subsection{INTRODUCTION}

On December 21, 1989, the EPA placed the U.S. Department of Energy's (DOE's) Oak Ridge Reservation (ORR) on the National Priorities List (NPL). On January 1, 1992, a Federal Facilities Agreement (FFA) between the DOE Field Office in Oak Ridge (DOE-OR), EPA Region IV, and the Tennessee Department of Environment and Conservation (TDEC) went into effect. This FFA establishes the procedural framework and schedule by which DOE-OR will develop, coordinate, implement, and monitor environmental restoration activities on the ORR in accordance with applicable federal and state environmental regulations. The DOE-OR Environmental Restoration Program for the ORR addresses the remediation of areas both within and outside the ORR boundaries, including Oak Ridge National Laboratory (ORNL) managed by Lockheed Martin Environmental Research Corporation, the former Oak Ridge Gaseous Diffusion Plant (K-25 Site), the Oak Ridge Y-12 Plant, Oak Ridge Associated Universities (ORAU), the Clinch River, and East Fork Poplar Creek (EFPC).

This sampling and analysis plan focuses on confirming the cleanup of the stretch of EFPC flowing from Lake Reality at the Y-12 Plant, through the City of Oak Ridge, to Poplar Creek on the ORR and its associated floodplain. Both EFPC and its floodplain have been contaminated by releases from the Y-12 Plant since the mid-1950s. Because the EFPC site-designated as an ORR operable unit (OU) under the Comprehensive Environmental Response, Compensation, and Liability Act (CERCLA) -is included on the NPL, its remediation must follow the specific procedures mandated by CERCLA, as amended by the Superfund Amendments and Reauthorization Act in 1986.

In accordance with CERCLA, a feasibility study was prepared to assess alternatives for remediation and a proposed plan was issued to the public in which a preferred alternative was identified. In response to public input, this plan was modified and DOE issued a Record of Decision in 1995 committing to excavation of all soil in the lower EFPC floodplain exceeding a concentration of 400 parts per million (ppm) of mercury.

This Field Sampling and Analysis Plan (SAP) presents the confirmation sampling work plan for the Lower EFPC remedial action in Oak Ridge, Tennessee. Post-excavation confirmation sampling is being conducted to confirm that mercury concentrations in the soils of the remediated areas are statistically less than, or equal to, the cleanup standard of $400 \mathrm{ppm}$. The U.S. Environmental Protection Agency's (EPA's) Methods for Evaluating the Attainment of Cleanup Standards, Volume 1: Soils and Solid Media, EPA 230/02-89-042, February, 1989, will be used as the methodology for determining the success of the cleanup.

\subsection{CHARACTERIZATION DATA}

\subsubsection{Site Description}

EFPC is a perennial stream located in Anderson and Roane Counties in Oak Ridge, Tennessee, $\sim 40 \mathrm{~km}$ (25 miles) west of Knoxville. Its headwaters are contained in 137- to 183-cm (54- to 72-in.) underground collection pipes that extend from the west end to the central area of the Y-12 Plant, 
where the above-ground portion of the creek begins. From the Y-12 Plant site, EFPC flows northward through a gap in Pine Ridge and enters Gamble Valley and the city of Oak Ridge. From there, the stream flows northwestward along Illinois Avenue through commercial and light industrial areas in Oak Ridge, then trends generally westward, parallel to Oak Ridge Turnpike in East Fork Valley, through primarily residential, agricultural, and undeveloped forest areas, until it joins Poplar Creek. EFPC waters, after entering Poplar Creek, flow into the Clinch River, which is impounded behind Watts Bar Dam.

From the point at which it exits Lake Reality to its confluence with Poplar Creek, EFPC measures $\sim 23 \mathrm{~km}$ (14.5 miles). Stream depths range from $<1 \mathrm{~m}$ to $3 \mathrm{~m}(3$ to $9 \mathrm{ft}$ ). The 100 -year floodplain bounding the creek varies in width from several meters in its upper reaches to $\sim 500 \mathrm{~m}$ (1640 ft) and encompasses $\sim 2.71 \mathrm{~km}^{2}$ (670 acres).

\subsubsection{Source of Contamination}

Beginning in 1952, the Y-12 Plant began production-scale separation of lithium isotopes, which required the use of millions of kilograms of mercury. This process released 108,000 to $212,000 \mathrm{~kg}$ $(239,000$ to $470,000 \mathrm{lb})$ of mercury into EFPC.

Although the primary discharges from the Y-12 Plant were eliminated in 1963, mercury continues to be released into EFPC from Y-12 Plant secondary sources (e.g., building drain systems, sewers, and connecting lines). The current release is $\sim 20 \mathrm{~g} / \mathrm{d}(0.7 \mathrm{oz} / \mathrm{d})$, down from $100 \mathrm{~g} / \mathrm{d}(3.5 \mathrm{oz} / \mathrm{d})$ in 1985 .

\subsubsection{Nature and Extent of Contamination}

The Remedial Investigation concluded that mercury was the principal contaminant of concern in the EFPC floodplain. The highest concentrations of mercury are in a visually distinct black layer of soil that typically lies 15 to $30 \mathrm{~cm}$ (6 to $12 \mathrm{in}$.) below the surface. Mercury contamination was found to be situated in distinct areas along the floodplain, and generally at depths $>20 \mathrm{~cm}(8 \mathrm{in}$.) below the surface. Based on the cleanup standard of $400 \mathrm{ppm}$ mercury and on sampling conducted by the Jacobs Engineering Group (JEG) since the remedial investigation, specific areas have been identified that require remediation at the National Oceanographic and Atmospheric Administration (NOAA) site along Illinois Avenue and at the Bruner site along the Oak Ridge Turnpike. The mercury contamination exceeding $400 \mathrm{ppm}$ at the NOAA site extends to a depth of $\sim 40 \mathrm{~cm}$ (16 in.), while at the Bruner site, the depth extends to $80 \mathrm{~cm}$ ( 32 in.) in isolated locations. The total identified in situ volume of contaminated floodplain soils is $\sim 19,100 \mathrm{~m}^{3}\left(25,000 \mathrm{yd}^{3}\right)$.

\subsection{PROJECT ORGANIZATION}

The EFPC remedial action is being conducted for DOE-OR as part of the Environmental Restoration (ER) Program by Lockheed Martin Energy Systems, Inc. (LMES). For the purposes of this remedial action, LMES is also the Remedial Action Contractor (RAC). MK-Ferguson, a subcontractor reporting to LMES, will be responsible for the construction activities. Science Applications International Corporation (SAIC) will provide confirmation sampling services as an LMES subcontractor reporting to MK-Ferguson. JEG will be the Independent Verification Contractor (IVC), who independently verifies that the cleanup has met the cleanup standard and then reports the results directly to DOE-OR. Key LMES, MK-Ferguson, and SAIC personnel affiliated with this investigation are listed in Table 1.1. 


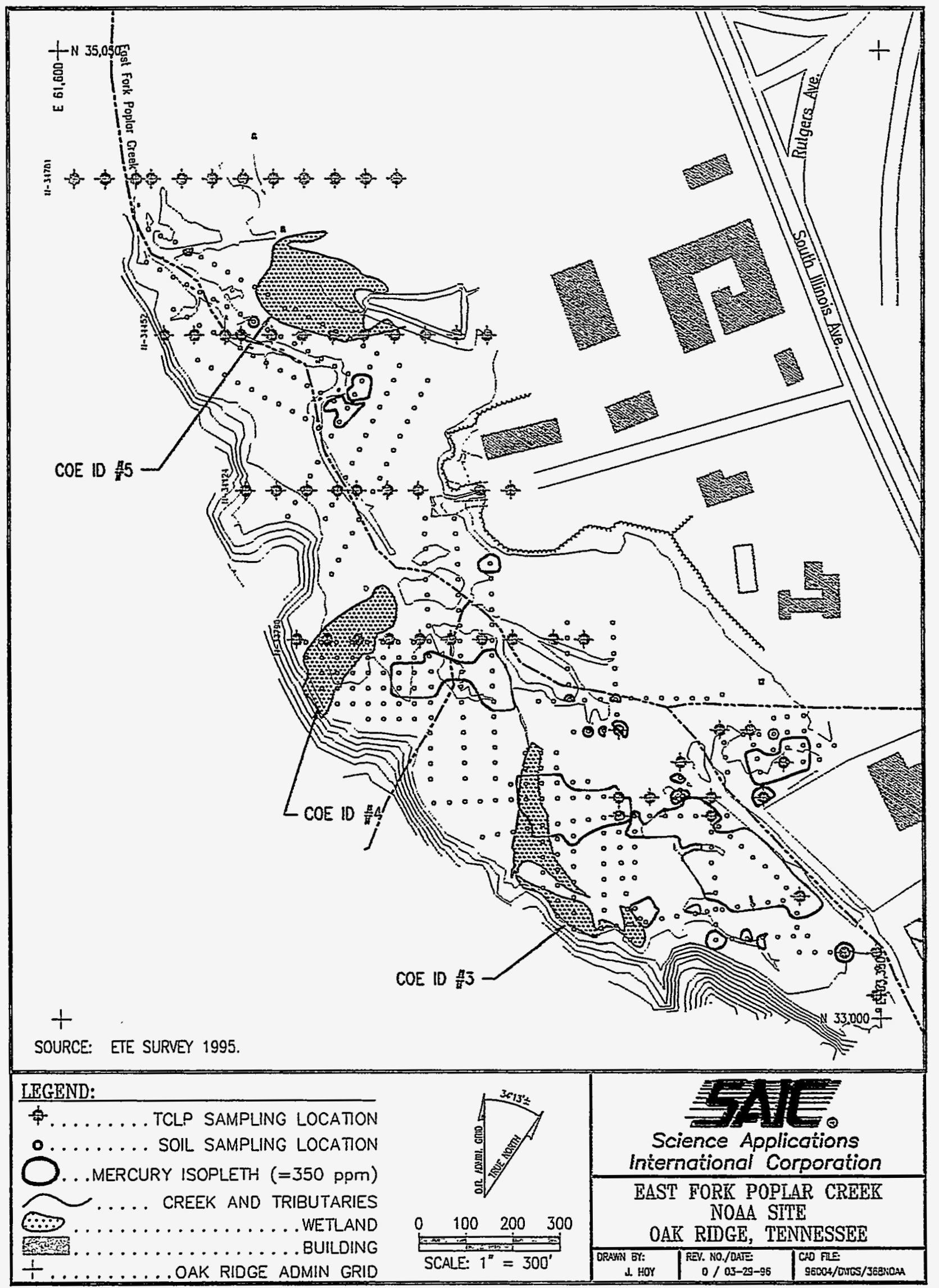

Fig. 1.1. East Fork Poplar Creek NOAA Site Oak Ridge, Tennessee. 


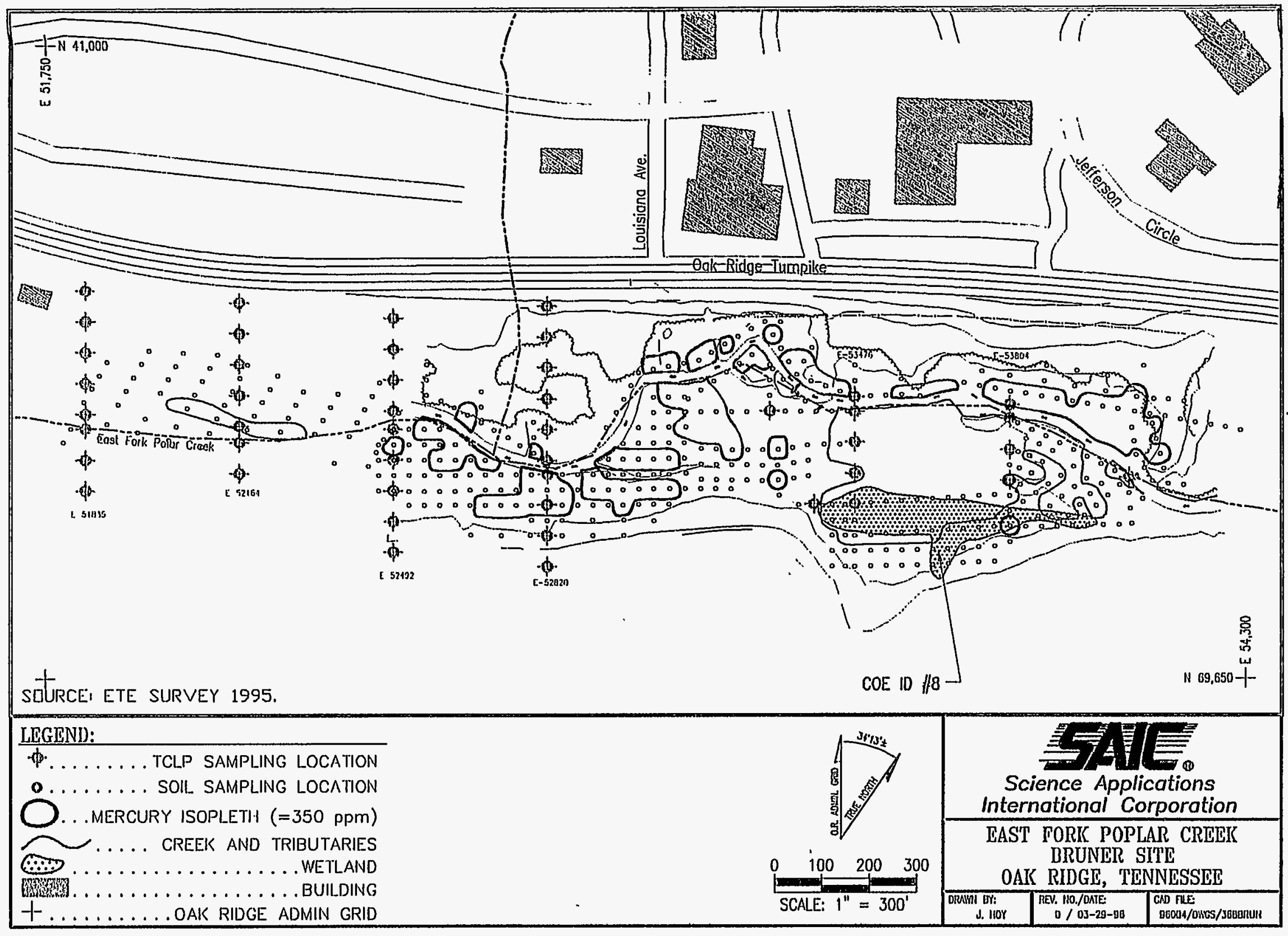

Fig. 1.2. East Fork Poplar Creek Bruner Site Oak Ridge, Tennessee. 
Table 1.1. Roles and responsibilities of the sampling team

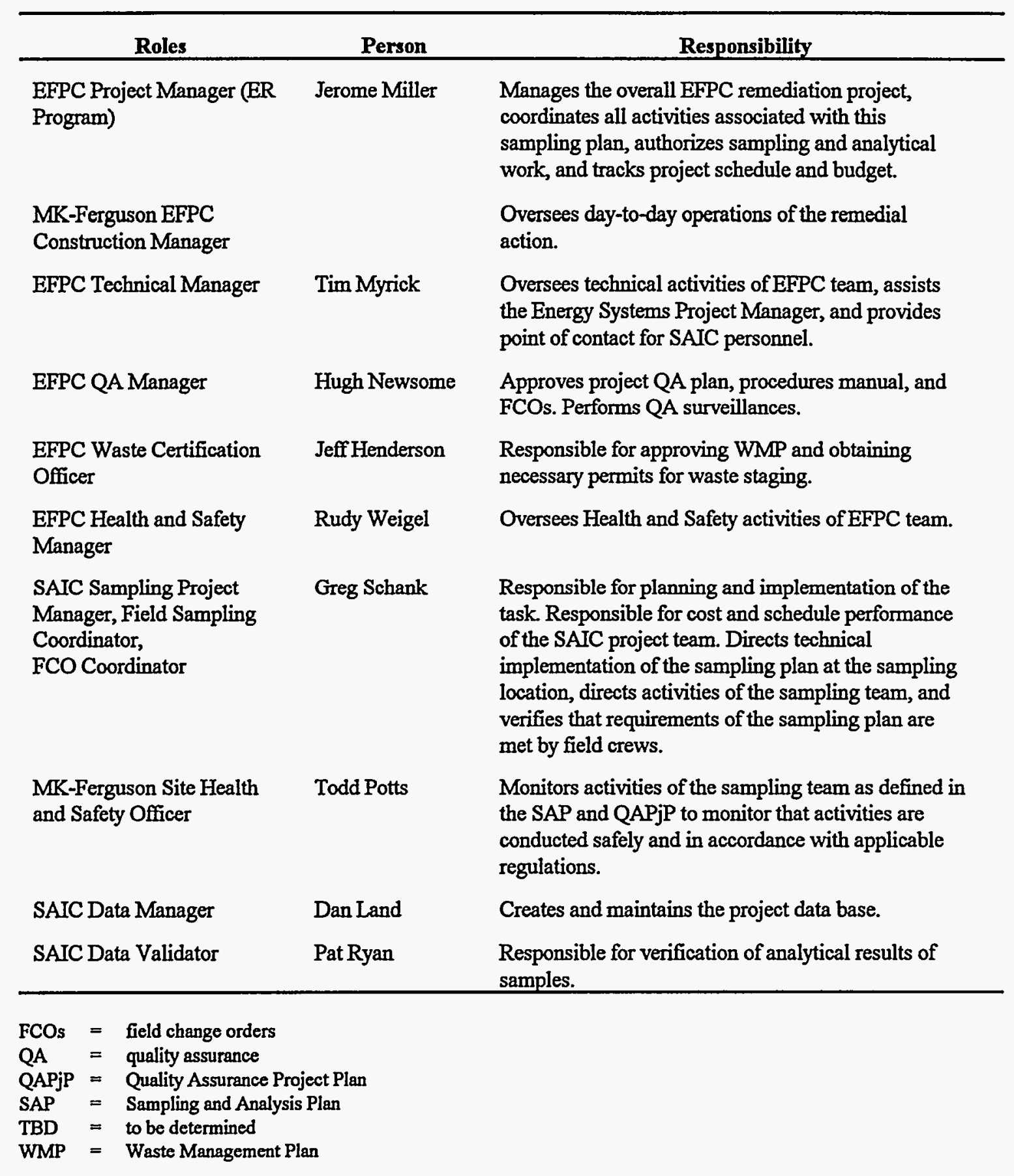




\subsubsection{Responsibilities and Coordination of Sampling Activities}

The remediation will occur in two phases. Phase I will occur at the NOAA facility in the spring of 1996 followed by full scale remediation (Phase II) scheduled for the spring of 1997. Phase I will provide an opportunity to refine the confirmation and verification process and test assumptions in this plan regarding sample turnaround time, verification time by the off-site laboratory, and daily field laboratory capacity. Problems identified during the Phase I remediation may require modification of the interactions described in this section.

Table 1.2 summarizes the division of duties between the RAC and IVC. The RAC will collect sufficient samples to document attainment of the remedial action objective. The IVC will independently verify that the quantity, quality, and location of samples collected are sufficient to demonstrate that the cleanup criterion has been attained. Verification will include review of the RAC remedial action plan, release criteria, procedures, and final survey documentation, and on-site visits and surveys involving sampling and/or split sample analyses, as necessary. The IVC may also recommend corrective actions for discrepancies.

Table 1.2. RAC/IVC responsibilities

\begin{tabular}{lll}
\hline & RAC & IVC \\
\hline Mission & Confirm cleanup & Verify cleanup \\
Objective & $\begin{array}{l}\text { Collect sufficient samples to } \\
\text { document success of cleanup }\end{array}$ & $\begin{array}{l}\text { Independently verify that quantity, } \\
\text { quality, and location of samples } \\
\text { collected by RAC are sufficient to } \\
\text { show that the cleanup criterion for } \\
\text { the site has been attained }\end{array}$ \\
$\begin{array}{lll}\text { Definition of excavation } \\
\text { boundaries }\end{array}$ & $\begin{array}{l}\text { Establish confirmation units' } \\
\text { locations for confirmatory }\end{array}$ & $\begin{array}{l}\text { Define contamination area } \\
\text { boundaries to identify limits of } \\
\text { sampling }\end{array}$ \\
analysis & excavation
\end{tabular}

Excavation boundaries will be defined by the IVC to identify limits of excavation. The RAC will establish the location of confirmation units within the contamination area boundaries for confirmatory sampling.

The RAC will collect screening samples to be analyzed in the field to help direct excavation during the remediation. When the RAC has indicated the confirmation unit has met the objectives, 16-in. deep confirmation samples will be taken and each sample composited over the full depth to confirm attainment. The confirmation samples collected by the RAC will be analyzed by an on-site laboratory. Analysis methodology is discussed in Sect. 2.10 of this document. Approximately $10 \%$ of the samples will be split for off-site laboratory analysis to compare on-site laboratory results for 
purposes of quality control. In addition to the quality control samples, up to $10 \%$ of the confirmation samples will be split with the IVC for verification. The IVC will have the option of taking separate 16-in. deep samples if deemed appropriate. All samples collected by the IVC will be analyzed at an off-site laboratory.

Both the RAC and the IVC will provide separate reports to DOE certifying the confirmation and verification of the cleanup, respectively. DOE will issue a Remedial Action Report containing confirmation and verification documentation certifying the site may be released free of restrictions. EPA and TDEC will review and approve the Remedial Action Report.

After a contaminated area is remediated, the RAC must demobilize from one area and move to another. When demobilization and remobilization are required, a data summary with validated results must be transmitted by the RAC to DOE in the form of a letter report. Based on IVC verification, DOE will then approve demobilization. Rapid feedback and approval will be required by EPA and TDEC.

\subsection{SAMPLING APPROACH}

\subsubsection{Sampling Objective}

Post-excavation confirmation sampling is being conducted to confirm that mercury concentrations in the soils of the remediated areas are statistically less than, or equal to, the cleanup standard of $400 \mathrm{ppm}$.

\subsubsection{Sampling Design}

EPA's Methods for Evaluating the Attainment of Cleanup Standards, Volume I: Soils and Solid Media, EPA 230/02-89-042, February, 1989, will be used as the methodology for determining the success of the cleanup.

Under this strategy, the contaminated areas within the boundaries identified during the remedial investigation (e.g., that were shown to exceed $400 \mathrm{ppm}$ mercury) are assumed to be contaminated until they are statistically proven to be clean. In the EPA description of this methodology, this approach is known as the Null and Alternative hypotheses approach. The Null hypothesis states that the area is presumed to be contaminated until the Alternative hypothesis is statistically shown to be true (i.e., samples taken from the site statistically show that the area is clean).

\subsubsection{Confirmation units}

The EPA method divides the site into sub-areas known as confirmation units (CUs) from which samples are to be randomly drawn subsequent to excavation to confirm that the cleanup has met the established standard. CUs of $232 \mathrm{~m}^{2}\left(2500 \mathrm{ft}^{2}\right)$ are recommended for this site based on the total area to be remediated, the pattern of mercury distribution, and the remediation schedule. Two types of CUs will be used. The Excavation Confirmation Unit (ECU) will provide complete coverage of the floor of the excavated areas. The Perimeter Confirmation Units (PCUs) will bound the ECUs. PCUs

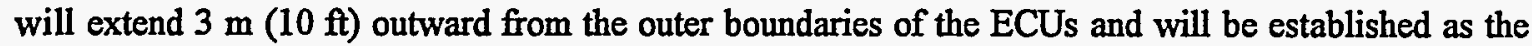
"clean" boundaries of the areas to be excavated (Fig. 1.3). The PCUs have been established by the IVC. 


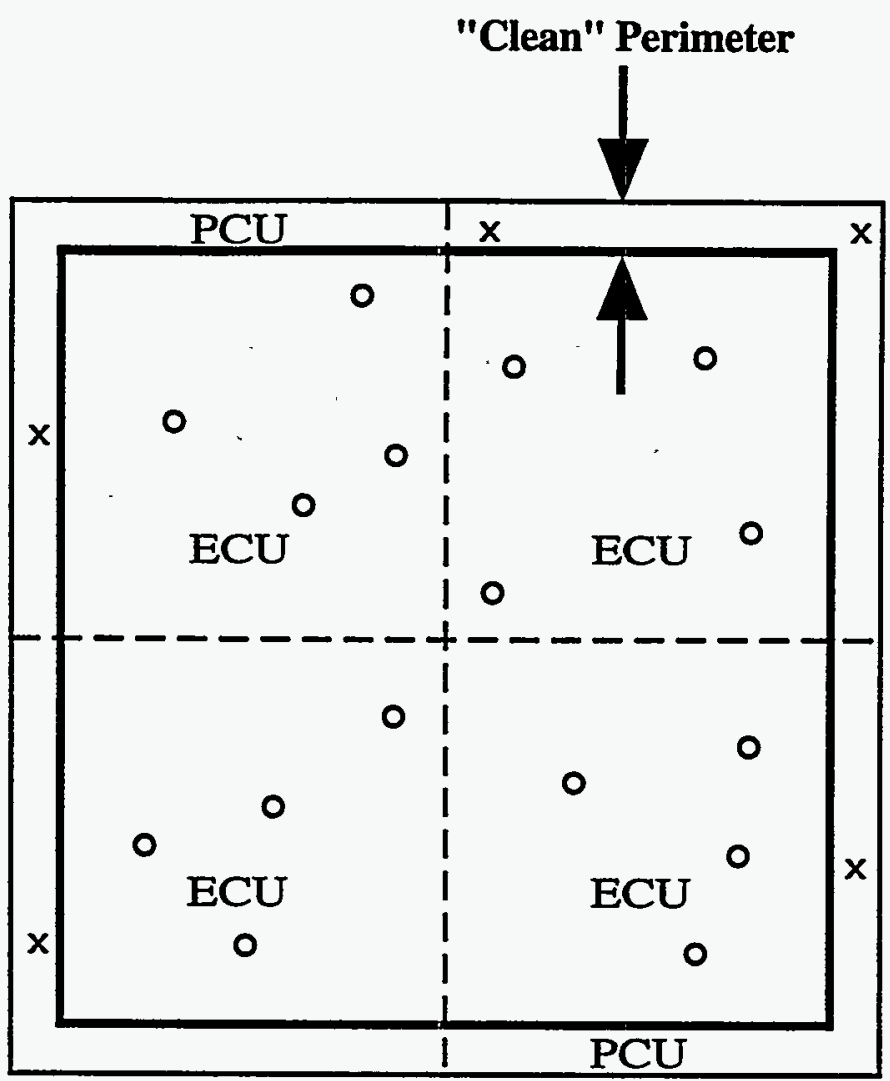

ECUi $=$ Excavation Confirmation Unit $(\leq 2,500$ sq. $\mathrm{ft}$. $)-$ excavated areas PCUi $=$ Perimeter Confirmation Unit $(\leq 2,500$ sq. $\mathrm{ft}$.) - "clean boundries" $x=$ Existing "clean" pre-remedial action samples - = Supplemental ECU samples for confirmation $---=$ Boundries between confirmation units

Fig. 1.3. Confirmation units. 
It is anticipated that 153 to $229 \mathrm{~m}^{3}$ (200 to $\left.300 \mathrm{yd}^{3}\right)$ of soil will be excavated on a daily basis. The average excavation depth will be $\sim 41 \mathrm{~cm}(16 \mathrm{in}$.). Therefore, the area to be excavated daily will range between 372 to $557 \mathrm{~m}^{2}$ (4000 to $\left.6000 \mathrm{ft}^{2}\right)$. A CU size of $232 \mathrm{~m}^{2}\left(2500 \mathrm{ft}^{2}\right)$ will permit 1 to 2 CUs to be verified daily allowing the RAC to respond quickly to stormflow conditions and other time critical conditions, thereby reducing the impacts of such conditions on the remedial action schedule. The actual number of samples that will be required for each CU depends not only on the acceptable error rates, but on the mean and standard deviation of the CU sample population.

\subsubsection{Determination of number of samples}

The number of samples required under the EPA methodology is based on:

- the false positive error rate $(\alpha)$,

- the false negative error rate $(\beta)$, and

- the mean $(\mu)$ and standard deviation $(\sigma)$ of the CU sample population.

A false positive error rate $(\alpha)$ is the probability that a $C U$ is incorrectly declared clean. A false negative error rate $(\beta)$ is when the $C U$ is incorrectly declared to be above the cleanup standard. In accordance with EPA recommendations for this project, an $\alpha$ of 0.01 has been chosen, which implies that there is 1 chance in 100 that an ECU may be incorrectly declared clean. The false negative rate $(\beta)$ is less critical from a health and safety standpoint, and therefore it has been set to 0.1 , which implies there is a 1 in 10 chance that a clean ECU will be declared dirty.

The equation for calculating the sample size is:

$$
n_{d}=\hat{\sigma}^{2}\left(\frac{Z_{1-\beta}+Z_{1-\alpha}}{C_{s}-\mu_{1}}\right)^{2}
$$

Equation 1

where:

Cs is the cleanup standard ( $400 \mathrm{ppm}$ mercury).

$\mu \quad$ is the "true" but unknown mean contaminant concentrations across the sample area, the population mean.

$\mu_{1} \quad$ is the value of $\mu$ under the alternative hypothesis for which a specified false negative rate is to be controlled $\left(\mu_{1}<\mu\right)$.

$\alpha \quad$ is the desired false positive rate for the statistical test. The false positive rate for the statistical procedure is the probability that the area will be declared clean when it is actually dirty.

$\beta \quad$ is the false negative rate for the statistical procedure is the probability that the sample area will be declared dirty when it is actually clean and the true mean is $\mu_{1}$. The desired sample size $n_{d}$ is selected so that the statistical procecture has a false negative rate of $\beta$ at $\mu_{1}$.

$n_{d}$ is the desired sample size for statistical calculations.

$\mathrm{n}$ is the final sample size (i.e., the number of data values available for statistical analysis including the concentrations that are below the detection level).

$\sigma$ is the standard deviation. The symbol "^" is used to denote that it is an estimate of $\sigma$ In practic, $\hat{\sigma}$ is either obtained from prior data or by conducting a small preliminary investigation.

$z_{1-\alpha}$, are the critical values for the normal distribution with probabilities of $1-\beta$ and $1-\alpha$.

Equation 1 requires that the sample values be approximately normally distributed. 
Based on the EPA guidance cited above, the mean concentration of the samples taken from an ECU should be compared to the cleanup standard to determine whether the area has been successfully remediated.

A difficulty with this method is that the actual mean and standard deviation of an ECU's sample population cannot be known until after the samples are obtained. Therefore, in order to specify the number of samples to be taken from each ECU, these parameters must be estimated. For this sampling and analysis plan, 74 randomly selected samples falling outside but within $3 \mathrm{~m} \mathrm{(10} \mathrm{ft)} \mathrm{of}$ the boundaries of the contaminated areas as defined by the RI and JEG characterizations were used as surrogates for the initial estimates of the ECU sample population statistics. The mean concentration of this population was $176 \mathrm{ppm}$ and the standard deviation was $99 \mathrm{ppm}$. Note that the actual floor of an ECU, after excavation, should yield samples with a substantially lower mean and standard deviation.

The distribution of the 74 samples was compared with a normal distribution using the ShapiroWilk statistic, $W$. The distribution was not significantly different from normal at the 0.05 probability level. The log-transformed values of the 74 samples were also compared with a normal distribution (to determine whether the sample population was log-normally distributed). This log-transformed distribution of values was found to be significantly different from a normal distribution. Therefore, use of EPA equation 1 is valid for the EFPC normally distributed dataset.

To estimate the number of samples to be taken from each ECU, the values of the parameters were based on the population characteristics of the 74 characterization samples and EPA recommended error rates. The following values were used in equation 1 :

$\begin{array}{ll}\alpha & 0.01 \text { yielding } \mathrm{a}\left(\mathrm{z}_{1-\alpha}\right) \text { of } 2.326 \\ \beta & 0.1 \text { yielding } \mathrm{a}\left(\mathrm{z}_{1-\beta}\right) \text { of } 1.282 \\ \mathrm{C}_{\mathrm{s}} & 400 \mathrm{ppm} \\ \mu_{1} & 200 \mathrm{ppm} \\ \hat{\sigma} & 10^{0} \mathrm{ppm}\end{array}$

Using Equation 1:

$$
n_{d}=100^{2}\left(\frac{1.282+2.326}{400-200}\right)^{2}=3.25
$$

Rounding up, four samples will be required from each ECU. It is likely that fewer samples will actually be required from each ECU; however, four will be taken from each ECU unless the unlikely condition occurs where an ECU's actual population values require a larger number of samples based on Equation 1. Then, the larger number of samples will be taken.

\subsubsection{Test of sample size validity}

To test whether four samples are sufficient, the Null and Alternative hypotheses are used. In order to statistically show that the cleanup standard was achieved for an ECU, the Alternative hypothesis must be shown to be true. The Alternative hypothesis is declared to be true only if the Null hypothesis is shown to be false based on significant contradictory data. When testing the mean, the Alternative hypothesis is that the ECU attains the cleanup standard and is expressed as $\mu<\mathrm{Cs}$. 
It is possible to calculate the confidence associated with the estimate of the true mean (e.g., how certain it is that $\mu_{1}$ closely approximates $\mu$ ).

An "upper one-sided 100(1- $\alpha)$ percent confidence limit around the population mean" is used to determine the success of the cleanup by applying a confidence estimate to the Null and Alternative hypotheses.

Itis expressed as:

$$
\mu_{U \alpha}=x+t_{1-\alpha, d f} \frac{s}{\sqrt{n}}
$$

where:

$\mu_{U a} \quad$ is the upper one-sided confidence limit,

$\overline{\mathbf{x}}$ is the computed mean level of contamination,

$s$ is the associated standard deviation,

$t_{1-\alpha, d f}$ is a statistical parameter determined by the desired level of confidence, and

$\mathrm{n}$ is the number of samples, including non-detects.

The Null and Alternative hypotheses are expressed with $100(1-\alpha)$ confidence as:

$$
\begin{aligned}
& \text { If } \mu_{U \alpha}<C s \text {, then the CU is clean (i.e., } \mu<C s \text { ). } \\
& \text { If } \mu_{U \alpha} \geq C s \text {, then the CU is dirty (i.e., } \mu \geq C s \text { ). }
\end{aligned}
$$

\subsubsection{Sample calculation}

A sample calculation based on the mean and standard deviation of the 74 samples (referenced above) is used to demonstrate the use of Equation 2. The following parameters were used to determine the confidence level associated with these data and to determine whether the cleanup standard is met using the Null and Alternative hypotheses (note the values are generally conservative).

$$
\begin{array}{ll}
\text { n } & 4 \text { (the typical number of samples to be taken from one } E C U) \\
\alpha & \left.0.05(95 \% \text { confidence), with } 3 \text { degrees of freedom (e.g., } n-1) \text {, yielding a ( } t_{1-\alpha, d}\right) \text { of } 2.353 \\
C_{z} & 400 \mathrm{ppm} \\
\bar{x} & 200 \mathrm{ppm} \\
\mathrm{s} & 100 \mathrm{ppm}
\end{array}
$$

Using Equation 2:

$$
\mu_{U \alpha}=200+2.353(100 / 2)=318
$$

Therefore, it can be stated with $95 \%$ confidence that the Alternative hypothesis is true.

$$
\mu_{U \alpha}=318<400
$$


In other words, based on the mean and standard deviation of the actual samples and the number of samples taken, it can be stated with $95 \%$ confidence that the true mean (no matter how many samples could be taken) is less than the cleanup standard of $400 \mathrm{ppm}$.

\subsubsection{Sampling Locations}

The individual sample locations must be randomly selected from within each ECU. The boundaries of the ECUs will be laid out on the floor of the excavated area using an instrumented survey or a Global Positioning System (GPS). The sampling team will establish an orthogonal grid for each ECU spaced at $1.5-\mathrm{m}$ (5-ft) intervals with the origin at the northwest corner and the grid lines oriented north-south and east-west. The intersection of each grid cell will be numbered beginning at 1 at the origin and increase from west to east. This will result in a total of $\sim 50$ to 100 numbered nodes per ECU depending on its size. The sampling team will then generate a random value between 0 and 1 . This value will be multiplied by the total number of nodes in the ECU and rounded to the nearest integer value. That integer value will be the first sampling location within the ECU. Integer values will continue to be randomly generated by the sampling team until four locations are defined from which samples can be obtained. The sample position will be recorded by instrumented survey or GPS subsequent to collection of the sample, but prior to backfill.

\subsubsection{Sampling Methods}

During the excavation, the RAC will take 2- to 8-in. deep screening samples to be analyzed in the on-site laboratory. These screening samples will be used as a tool to guide the excavation and help the RAC determine when to formally sample for confirmation of the cleanup. The screening samples will not be subject to the same analytical rigor as the confirmation and verification samples. Screening samples will not be used to document the cleanup.

Confirmatory soil samples will consist of a 16-in. core taken at the randomly selected nodes and taken perpendicular to the ground surface using a JMC Backsaver Soil Sampler and following the procedure BCV OU1-3030-8, Subsoil Sampling with a JMC Backsaver Soil Sampler System, and composited using procedure ESP-308-1, Composite Procedures. Each 16-in. sample will be dried and composited over the full depth of the sample prior to splitting and analysis.

\subsubsection{Sample Handling}

Soil samples will be collected to confirm mercury remediation levels have been achieved. Each confirmatory sample will be analyzed for mercury by the on-site laboratory. The laboratory analytical methodology is discussed in Sect. 2.10 of this document. In addition, $10 \%$ of the samples will be sent to an off-site laboratory for analysis. A split sample will be supplied to the IVC, as requested. Finally, a portion of each sample will be archived in the event additional analysis is required.

\subsubsection{Chain of custody}

Sample chain of custody will be maintained in accordance with ESP-501, Chain of Custody.' Sample custody will be initiated at the time of sample collection. Field samples will be identified by sample tags and labels. Descriptions of sampling activities and sample identification data will also be recorded in field logbooks. Field chain-of-custody forms containing the same information will be completed for each set of samples. A line item on the sample chain-of-custody form will be completed for each sample, and the sample collector will confirm the completeness and accuracy of all information entered on the form by the sampling team. Each individual who assumes custody of the samples will sign and date the chain-of-custody form. . 
Field custody procedures include the following steps:

- Before sampling begins, the Quality Assurance/Quality Control (QA/QC) Officer or designee will instruct sampling personnel on the chain-of-custody and sample labeling procedures.

- A chain-of-custody form will be initiated at the time of collection of each sample.

- Each time sample custody is transferred, the person relinquishing the sample and the new custodian will sign the chain-of-custody form and record the date and time of transfer.

- The analyses to be performed for each sample will be recorded on the chain-of-custody form accompanying the samples to the laboratory.

- The field team leader will confirm that proper custody procedures are followed during the field work in the field logbook.

\subsubsection{Sample packaging and transportation}

Samples taken for shipment to the off-site laboratory will be classified, handled, and packaged in accordance with ER/C-P2302, Sample Classifying, Packaging, Labeling, and Shipping for Analysis Through the K-25 and Y-12 ER Programs (IAD). The off-site laboratory used for this investigation will be a qualified analytical laboratory. Samples will be shipped in accordance with U.S. Department of Transportation (DOT) regulations on a daily basis, when collected, by a member of the field team. Samples collected for analysis by the on-site laboratory will be properly preserved (as described in ESP-701, Sample Preservation and Container Materials) following collection and hand delivered to the on-site laboratory.

\subsubsection{Sample containers, sample preservatives, and holding times}

The selection criteria for appropriate sample containers, sample preservatives, and holding times will be in accordance with ESP-701 Sample Preservation and Container Materials. Types of sample containers and preservatives used will be documented in the sampling logbook. Field and laboratory records will indicate the holding times before analysis.

\subsubsection{Sample identification and traceability}

Each sample collected during this investigation will be assigned a unique six-character sample identifier which will be permanently affixed to the sample container and recorded in the field logbook and on the chain-of-custody forms. The sample identifier will have four elements. It will be necessary to distinguish samples taken by the RAC from the ECUs from those taken by the IVC from the PCUs. Therefore, the first element is a letter that indicates whether the sample is from a perimeter $(\mathrm{P})$ or excavation $(\mathrm{E})$ confirmation unit. The second element is a three-digit number that specifies the confirmation unit. The third element is a one-digit number that specifies the sample position within the confirmation unit. The last element is an alphanumeric character that specifies the sample type. The possible values for each element are listed in Table 1.3. For example, sample E1001D would be a field duplicate sample from position 1 in excavation confirmation unit 100 . 
Table 1.3. Elements of sample identifier

\begin{tabular}{lccl}
\hline $\begin{array}{c}\text { 1st Element } \\
\text { Unit type }\end{array}$ & $\begin{array}{c}\text { 2nd Element } \\
\text { Unit number }\end{array}$ & $\begin{array}{c}\text { 3rd Element } \\
\text { Position number }\end{array}$ & \multicolumn{1}{c}{$\begin{array}{c}\text { 4th Element } \\
\text { Sample type }\end{array}$} \\
\hline P = Perimeter & 000 & 0 & 1 = confirmation sampling \\
E= Excavation & to & to & 2 to $9=$ subsequent resamplings \\
& 999 & 9 & $\mathrm{~B}=$ field blank \\
& & $\mathrm{D}=$ field duplicate \\
& & $\mathrm{S}=$ split sample \\
& & $\mathrm{R}=$ equipment rinsate \\
\hline
\end{tabular}

\subsubsection{Field documentation}

An integral part of the QA/QC plan for the field activities will be to maintain current, accurate, and complete field records, including logbooks and chain-of-custody forms. Field logbooks will be of hard-cover construction with consecutively numbered pages. Information pertaining to the field activities and information required in ESP-501, Chain of Custody, Sect. VII, Part D, will be recorded. Entries in the logbooks and on chain-of-custody forms will be made in black indelible ink. Corrections will be marked out with a single line, initialed, and dated. To maintain dual storage of records, field logbooks will be photocopied once a week, and the copies will be maintained at the SAIC office. When field work is complete, copies will be made of the completed logbooks, the copies entered into the SAIC Central Records Facility and the project file, and the original forwarded to the ER Records Center. MK-Ferguson will also receive copies of the completed logbooks.

\subsubsection{Decontamination}

All sample containers used will be new and accompanied by certificates of analysis. Therefore, sample containers will not require decontamination. The decontamination of sampling devices will follow Attachment II, Sect. VI of ESP-801, Cleaning and Decontamination of Sample Containers and Sampling Devices. This procedure requires the following:

- cleaning with tap water and phosphate-free laboratory detergent, using a brush if necessary to remove particulate matter and surface films;

- $\quad$ rinsing thoroughly with tap water;

- rinsing thoroughly with deionized or organic-free water;

- $\quad$ rinsing twice with pesticide-grade isopropyl alcohol;

- rinsing thoroughly with organic-free water and allowing equipment to air dry as long as possible; and

- wrapping with aluminum foil (dull side in) if appropriate, to prevent contamination, if equipment is to be stored or transported.

Decontamination of sampling equipment will be conducted at a decontamination line established near the on-site laboratory trailer. Sampling equipment will be decontaminated prior to sampling at each location and at the completion of sampling. The management of decontamination wastes is discussed in the waste management plan for this investigation. 


\section{QUALITY ASSURANCE PROJECT PLAN}

\subsection{INTRODUCTION}

This Quality Assurance Project Plan (QAPjP) has been developed to define the quality-related requirements for the EFPC Remedial Action confirmation analysis. This document has been prepared in accordance with DOE Order 5700.6C, Quality Assurance and includes the following elements: project description, organization and responsibilities, functional activities, and specific protocols that will be followed for sampling, chain of custody, calibration, laboratory analysis, data reduction, verification/validation, and data reporting. Table 2.1 provides a comparison matrix of this QAPjP to DOE Order 5700.6C.

\subsection{PROJECT DESCRIPTION}

\subsubsection{Background}

The EFPC floodplain sediments were contaminated with mercury as a result of past Y-12 Plant operations and practices. Through implementation of CERCLA investigations, contamination has been characterized, its extent has been documented, remedial alternatives have been evaluated, and remedial action has been selected. This remediation will excavate soils within the floodplain from locations identified near the NOAA facility and the Bruner site.

\subsubsection{Project Scope}

This study will be conducted to confirm achievement of the remediation criteria established for the EFPC floodplain soils. Data will be used to obtain a statistical confidence that each ECU has mean mercury concentrations levels $s 400 \mathrm{ppm}$. The scope of this work will include the collection and analysis of four subsurface soil samples at randomly selected locations within each ECU.

\subsection{PROJECT ORGANIZATION AND RESPONSIBILITIES}

SAIC will conduct this operation as an LMES subcontractor reporting to MK-Ferguson. SAIC will use an integrated team of staff professionals to accomplish the objectives of this work. The project organization is identified in Sect. 1.3 and roles and responsibilities are provided in Table 1.1.

\subsection{READINESS REVIEW}

Approximately three weeks prior to mobilization for the sampling effort, SAIC will conduct a readiness review following QAAP 2.2. The readiness review will be attended, at a minimum, by the SAIC Project Manager, QA/QC Officer (or designee), Health and Safety Manager (or designee), Field Operations Manager (MK-Ferguson), and Analytical Laboratory Coordinator. Appropriate representatives of OR-DOE, LMES, and JEG, may also attend. 
Table 2.1. Comparison of QAPjP to DOE Order 5700.6C

\begin{tabular}{|c|c|}
\hline QAPjP Section & DOE Order 5700.6C \\
\hline Title Page & $\begin{array}{l}\text { General } \\
\text { 4. Documents and Records }\end{array}$ \\
\hline Table of Contents & $\begin{array}{l}\text { General } \\
\text { 4. Documents and Records }\end{array}$ \\
\hline Project Description, Sect. 2.2 & $\begin{array}{l}\text { General } \\
\text { 2. Personnel Training } \\
\text { 7. Procurement }\end{array}$ \\
\hline Project Organization and Responsibilities, Sect. 2.3 & $\begin{array}{l}\text { General } \\
\text { 2. Personnel Training }\end{array}$ \\
\hline QA Objectives, Sect. 2.6 & 1. Management Program \\
\hline Field Activity Procedures, Sect. 2.7 & $\begin{array}{l}\text { 4. Documents and Records } \\
\text { 6. Design }\end{array}$ \\
\hline Calibration Procedures and Frequency, Sect. 2.9 & $\begin{array}{l}\text { 5. Work Processes } \\
\text { 7. Procurement } \\
\text { 8. Inspection and Test }\end{array}$ \\
\hline Analytical Procedures, Sect. 2.10 & $\begin{array}{l}\text { 6. Design } \\
\text { 7. Procurement }\end{array}$ \\
\hline Data Reduction, Verification, Validation, and Reporting, Sect. 2.11 & $\begin{array}{l}\text { 5. Work Processes } \\
\text { 6. Design }\end{array}$ \\
\hline Internal Quality Control, Sect. 2.12 & $\begin{array}{l}\text { 5. Work Processes } \\
\text { 6. Design }\end{array}$ \\
\hline Assessments, Sect. 2.13 & $\begin{array}{l}\text { 9. Management Assessment } \\
\text { 10. Independent Assessment }\end{array}$ \\
\hline $\begin{array}{l}\text { Preventive Maintenance Procedures and Schedules, } \\
\text { Sect. 2.14 }\end{array}$ & $\begin{array}{l}\text { 5. Work Processes } \\
\text { 8. Inspection and Test }\end{array}$ \\
\hline Investigation Criteria, Sect. 2.6 .2 & $\begin{array}{l}\text { 5. Work Processes } \\
\text { 8. Inspection and Test }\end{array}$ \\
\hline Corrective Action Procedures, Sect. 2.15 & $\begin{array}{l}\text { 3. Quality Improvement } \\
\text { 9. Management Assessment } \\
\text { 10. Independent Assessment }\end{array}$ \\
\hline QA Reports to Management, Sect. 2.16 & $\begin{array}{l}\text { 4. Document and Records } \\
\text { 9. Management Assessment } \\
\text { 10. Independent Assessment }\end{array}$ \\
\hline
\end{tabular}

Bold type indicates primary corresponding requirement in $5700.6 \mathrm{C}$.

Non-bold type indicates topic contained within context of criteria but not specifically the same requirement. 
The readiness review follows a checklist and determines project readiness by documenting that workplans and procedures are approved, controlled, and distributed; that site logistics have been handled; that proper equipment, materials, and resources are available; that the laboratory is ready to accept samples, that the field laboratory operation is prepared to operate; and that the QA system will be implemented during field and analytical activities.

Prior to the readiness review, the SAIC Project Manager will prepare a list of participants and submit a readiness review notification to the affected personnel. The readiness review checklist will be completed during the review meeting and objective documentation of readiness will be attached. The checklist will be reviewed by the QA/QC Officer and submitted to the SAIC Central Records Facility (CRF) and the DOE-OR and LMES Project Manager.

\subsection{PROJECT TRAINING}

Training required for this investigation includes that related to health and safety, site access, and project-specific procedures. Training will be completed prior to the commencement of field activities. Training in project-specific procedures will be completed by reading assignments or classroom lectures in accordance with QAAP 2.1 Indoctrination and Training and demonstrating required knowledge and skills by satisfactorily completing a test on the subject matter or demonstrating performance. Training of this type will be documented by the completion of Training Assignment Records which will be signed by all field personnel. Documentation of required training will be maintained in the CRF, the ER Document Center, the ER Project Manager's project file, and in the field during the investigation.

\subsection{QA OBJECTIVES FOR DATA MEASUREMENT}

\subsubsection{Intended Uses of Acquired Data}

Data generated by this investigation are intended to document attainment of the EFPC cleanup goals for mercury contamination.

\subsubsection{Investigation Criteria}

To collect data that are suitable for their intended use, investigation criteria were determined based on existing data. Investigation criteria include the number of samples to be collected, analyses to be performed, level of QA/QC in sampling and analysis, and data validation/verification criteria. Justification for the number and locations of samples is provided in Sect. 1.4. The level of QC for this investigation is presented in Sect. 2.12 of this QAPJP. Validation/verification criteria are presented in Sect. 2.11. To satisfy investigation criteria, data collected in this investigation will be accurate, scientifically valid, and legally defensible. To accomplish this, data will be collected or developed in accordance with established and approved QA procedures. Additionally, the data collected will be of measurable precision, accuracy, representativeness, completeness, and comparability (PARCC). Investigation objectives for the PARCC parameters are defined in the following sections. The values associated with these parameters are included here as goals and will be subject to continuous review by the SAIC data manager. 


\subsubsection{Precision}

Precision is a measure of the reproducibility or degree of agreement between individual measurements of the same property under prescribed similar conditions. Precision will be expressed in terms of the relative percent difference (RPD) from the average value obtained from duplicate analyses. For this investigation, the precision goal is an RPD of $<20 \%$ or an absolute difference of $\pm 2 \times$ the detection level for values $<10 \times$ the detection level for mercury analytical duplicates. Both field and fixed analytical laboratories will complete analytical duplicates for $5 \%$ of the samples analyzed. Additionally, 1 field duplicate will be collected from each ECU to assess the precision of sample collection procedures. The precision goal for mercury in field duplicates is an RPD of $<30 \%$ or an absolute difference of $\pm 3 \times$ the detection level for values $<10 \times$ the detection level.

\subsubsection{Accuracy}

Accuracy is a measure of the potential bias in a measurement system, or the degree of agreement of a measurement " $X$ " with an accepted reference or true value " $T$." Standards, spiked samples, and reference samples will be used to assess the accuracy of results. The accuracy goal for this project is no more than $20 \%$ difference between measured and true value for mercury.

\subsubsection{Representativeness}

A sample should represent the composition of the medium at the sampling point so that the analytical results can be used to evaluate contaminant concentration at the site. A sample's representativeness can be obtained by using standard field-sampling collection and handling procedures, and by properly decontaminating sampling equipment before samples are collected. Standard operating procedures have been established and will be followed for this investigation. The statistical sampling approach defined for this confirmation analysis will allow confidence levels to be determined for ECUs and PCUs.

\subsubsection{Completeness}

Completeness is a measure of the amount of valid data obtained from a measurement system compared to the amount expected to be collected under normal conditions. For this investigation, the completeness objective for sampling is $95 \%$ of samples planned and the completeness objective for analysis is $95 \%$ of the samples collected.

\subsubsection{Comparability}

Consistency in the acquisition, handling, and analysis of samples is used to compare the results with other investigations. For comparability of analytical results with those obtained in other investigations, the samples will be collected and analyzed by generally accepted methods.

\subsection{FIELD ACTIVITY PROCEDURES}

This investigation will consist of the collection and analysis of soil samples. For quality and consistency of data, specific approved sample collection and handling procedures from LMES Environmental Surveillance Procedures Quality Control Program ES/ESH/INT-4 (Kimbrough et. al 1990), from Y-12 Plant ER Program Operating Instructions, and from the SAIC Field Technical Procedures Manual will be followed. Specific procedures that will be implemented are listed in Table 2.2. 
Table 2.2. Field Procedures for the EFPC remediation confirmation analysis

\begin{tabular}{|c|c|}
\hline Procedure & Procedure title \\
\hline \multicolumn{2}{|r|}{ Sample Collection } \\
\hline BCV OU1-303-8 & $\begin{array}{l}\text { Subsoil Sampling with a JMC Backsaver Soil Sampler } \\
\text { System }\end{array}$ \\
\hline ESP-308-1 & Composite Procedures \\
\hline \multicolumn{2}{|r|}{ On-site Laboratory Screening } \\
\hline $\begin{array}{l}\text { Environmental } \\
\text { Sciences Division } \\
\text { Procedure }\end{array}$ & $\begin{array}{l}\text { Static Headspace Analysis for Mercury in Soils } \\
\text { (Appendix A) }\end{array}$ \\
\hline \multicolumn{2}{|r|}{ Sample Handling } \\
\hline ESP-501 & Chain of Custody \\
\hline ER/C-P2302 & $\begin{array}{l}\text { Sample Classifying, Packaging, Labeling and Shipping for } \\
\text { Analysis through the K-25 and Y-12 ER Programs (IAD) }\end{array}$ \\
\hline ESP-701 & Sample Preservation and Container Materials \\
\hline ESP-801 & $\begin{array}{l}\text { Cleaning and Decontamination of Sample Containers and } \\
\text { Sampling Devices }\end{array}$ \\
\hline \multicolumn{2}{|r|}{ Other } \\
\hline ER/C-P1719 & $\begin{array}{l}\text { Controlling and Documenting Field Changes to Approved } \\
\text { Field Sampling Plans }\end{array}$ \\
\hline
\end{tabular}

Prior to mobilization, SAIC will prepare a manual that will include all procedures that will be implemented in the field. Modifications to LMES procedures will be indicated on cover sheets attached to each procedure. The procedures manual, including the procedure modifications, will be submitted to the LMES ER Project Manager and ER QA Specialist for approval. The procedure manual will be controlled by and will be distributed to all appropriate project personnel, the ER Document Center, and the MK-Ferguson.

\subsubsection{Field Variance System}

Procedures cannot fully encompass all conditions encountered during a field investigation. Variances from the operating procedures, the SAP, and/or the SAIC Site and Task Specific Health and Safety Plan (HASP), therefore, may be necessary. To document variances and variance approval, procedure ER/C-P1719 Controlling and Documenting Field Changes to Approved Sampling Plans will be followed as described below.

ER/C-P1719 classifies Field Change Orders (FCOs) as "Minor," "Major," or "other." During the investigation, any FCO requests that are thought to be classified as "Major" or "Other" will be routed and handled as described in ER/C-P1719.

FCO requests that are classified as "Minor" will be handled in the following manner. Upon recognition of the need for a variance, the field operations manager will complete an FCO Form and will contact the DOE ER Project Manager or designee for verbal approval of the FCO. If the FCO 
is approved, the field operations manager will note approval, the nature of the FCO, and the FCO number in the field activities logbook, and a copy of the unsigned FCO form will be maintained in the FCO control $\log$ in the field. The variance may then be implemented. Within $24 \mathrm{~h}$, the field team leader will route an additional copy of the unsigned FCO Form to the FCO Coordinator. The SAIC FCO Coordinator will log the FCO and route it to the DOE Project Manager and ER QA Specialist for signature approval. A copy of the approved FCO form will be routed to the Field Team Leader, who will replace the unsigned FCO with the approved, signed copy. All FCOs that request variance from the HASP, regardless of classification, will be approved by the Health and Safety Manager.

\subsection{SAMPLE CUSTODY PROCEDURES}

\subsubsection{Field Sample Custody}

Samples will be collected by field sampling personnel and sample custody will be initiated at the time of sample collection. Field samples will be identified with appropriate labels. Descriptions of all sampling activities and sample identification data will be recorded in field logbooks. Field chain-of-custody forms containing all relevant information will be completed for each sample. The sampling technician will confirm by signature the completeness of the information on the form. Each subsequent individual who assumes responsibility for the samples will sign and date the chain-ofcustody form.

Field chain-of-custody forms will accompany the samples from the sampling point to the on-site laboratory. Upon receipt, the on-site laboratory will verify the information on the custody form and the sample container, accept custody, sign the custody form, and commence analysis. The on-site laboratory will maintain custody of all samples until sample disposal or until selected samples are transferred to the off-site laboratory for analytical confirmation.

\subsubsection{Laboratory Sample Custody}

Selected samples will be shipped in accordance with DOT regulations to a qualified laboratory. Upon receipt, a member of the off-site laboratory will accept custody of the samples and will document the following:

- seals on the transportation container are unbroken,

- individual sample containers within the sample transportation container are intact and properly preserved,

- identification on the sample containers correspond to the entire description on the chain-ofcustody form, and

- number of sample containers received is equal to the number listed on the chain-of-custody form(s).

If discrepancies are found, the SAIC Project Manager or designee shall be called immediately to rectify them. Discrepancies will be recorded on appropriate forms and on the chain-of-custody form (if appropriate), with incorrect information marked out with a single line, initialed, and correct information added. Once samples are in the custody of the laboratory, their internal chain-of-custody and sample handling procedures will be followed. 


\subsection{CALIBRATION PROCEDURES AND FREQUENCY}

\subsubsection{Field Instrument Calibration}

Field measurement and test equipment used for this investigation will include mercury vapor analyzers. Only those anatyzers that are within manufacturex's calibration will be used. A minimum of one-point response checks of the analyzers will be performed daily, by SAIC persomel, following the manufacturer's instructions manual. Additional or more frequent chocks will be performed if conditions warrant.

A minimum of a four point initial method calibration will be performed for static mercury vapor headspace analysis in soils. This will include a method blank and a standard near the anticipated method detection level. This initial method calibration will be checked through analysis of a continuing calibration check standard after every ten sample analyses.

Equipment inventory, calibration, and use will be recorded in a field logbook. The equipment inventory will include the description, unique identifier, and calibration recall dates of each piece of equipment present in the field. Calibration records will include the instrument identifier, the date and time of calibration, the person performing the calibration, and a complete description of calibration standards used including source type, lot number, and expiration date. Equipment use will be included in the field logbook. Recorded information will include, at a minimum, the unique identifier of equipment used, the date and time of use, and the measurement results. Calibration status will be stickered on instruments.

\subsubsection{Off-site Laboratory Instrument Calibration}

Laboratory equipment will be calibrated according to the procedures specified in the analytical methods and in the operating procedures for the particular instrument. Calibration frequency will be based on the analytical methods employed, type of equipment, inherent stability, manufacturer's recommendations, values given in national standards, intended use, and experience. For mercury analysis this routinely requires daily multi-point calibration. Calibration and maintenance records will be kept with the equipment. Calibration control charts shall be maintained for instruments used in analyses of samples. Copies of control charts will be transmitted with data packages to demonstrate control of these instruments. Calibration data for each instrument used in analysis will be transmitted to data validators for verification. Calibration frequencies and procedures as designated in the CLP routine analytical services statement of work will be followed.

For laboratory equipment, Class A volumetric glassware will be used to prepare calibration standards, bench standards, samples for analysis, etc.

\subsection{ANALYTICAL PROCEDURES}

Mercury is the single analyte of interest required for this confirmation analysis. Determination of mercury soil concentrations will be determined through implementation of a field screening method at an on-site laboratory facility. The analytical procedure to be followed is the Static Headspace Analysis for Mercury in Soils (Kriger and Turner 1996, in press). The quantitation limit goal for implementation of this method is $1 \mathrm{mg} / \mathrm{kg}$ of soil. Off-site laboratory analysis for confirmation of these on-site determinations will be performed using CLP ILM3.0 protocols for mercury analysis by cold vapor atomic absorption spectroscopy. Quantification limit goals for this analysis will be $0.2 \mathrm{mg} / \mathrm{kg}$. Additional requirements are specified in the analytical protocols for each methodology. 


\subsection{DATA REDUCTION, VERIFICATION, VALIDATION, AND REPORTING}

\subsubsection{Data Reduction and Verification}

Field data and observations recorded in the field logbooks will be yerified daily by a sample team member other than the member who originally recorded the data. Once the sampling logbooks have been completed in the field, they will be transferred to the SAIC Project Manager. The SAIC Project Manager will review the data from the sampling logbooks and chain-of-custody records and verify that the data are recorded correctly and completely and that all field instruments were properly calibrated. Any problems with the field data will be documented by the completion of a nonconformance report (NCR).

On-site mercury screening data will be reduced and reviewed by the field analyst in accordance with the analytical method. All data and calculations will be documented in the on-site laboratory notebook. All on-site measurements will be verified and validated by the SAIC Project Manager or designee. Any problems or discrepancies will be documented by the completion of an NCR.

Off-site confirmatory analytical data will be reduced and reviewed by the off-site laboratory in accordance with the analytical procedures and the internal QA program of the off-site laboratory. As data packages are received, they will be copied, logged in, and the sample delivery group information will be linked to the field sample IDs. Project staff will verify the data by (1) recording the receipt of analytical results from the laboratory, (2) verifying that the analyses were performed for the desired parameters using proper analytical methods, (3) verifying that the results were reported in proper measurement units and are within known method-specific ranges, and (4) verifying that the laboratory data packages are complete and contain required QC forms and documentation. Problems with the analytical data will be documented by the completion of NCRs.

\subsubsection{Data Validation}

Data validation will be consistent with the specifications as outlined in Requirements for Quality Control of Analytical Data for the Environmental Restoration Program (ES/ER/TM-16). All project data will be evaluated to ensure a complete, consistent, and usable project data set. All project mercury data will be validated based on validation criteria as described below. The data validation criteria listed below have been determined as critical in the evaluation of analytical data usability. These are based on analytical process knowledge and known to contribute significantly to the potential analytical qualification and associated uncertainty of the reported results. Evaluation will allow identification of potential false positive or negative results.

Mercury data validation categories are as follows.

On-site analysis

Holding Times

Blanks

Laboratory Control Sample

Initial Calibration

Continuing Calibration

Duplicate Analysis

Sample Reanalysis

Secondary Dilutions

Field Laboratory Notebooks
Off-site analysis

Holding Times
Blanks
Laboratory Control Sample
Initial Calibration
Continuing Calibration
Duplicate Analysis
Sample Reanalysis
Matrix Spike Analysis
Secondary Dilutions
Case Narrative




\subsubsection{Data Validation Criteria}

Holding Times. Evaluation of holding times ascertains the validity of results based on the length of time from sample collection to sample preparation or sample analysis. Verification of sample preservation must be confirmed and accounted for in the evaluation of sample holding times. The evaluation of holding times is essential to establishing sample integrity and representativeness. Concerns regarding physical, chemical, or biochemical alteration of analyte concentrations can be eliminated or qualified through this evaluation. The holding time for mercury in soil is $28 \mathrm{~d}$, while preservation requires containerization in plastic or glass.

Blanks. The assessment of blank analyses is performed to determine the existence and magnitude of contamination problems. The criteria for evaluation of blanks applies to any blank associated with the samples, including field, trip, equipment, and method blanks. Contamination during sampling or analysis, if not discovered, results in false positive data.

Calibration. The purpose of initial and continuing calibration verification analyses is to verify the linear dynamic range and stability of instrument response. Relative instrument response is used to quantify the analyte results. If the relative response factor is outside acceptable limits, the data quantification is uncertain and requires appropriate qualification.

Sample Reanalysis. When instrument performance-monitoring standards indicate an analysis out-of-control, the laboratory is required to reanalyze the sample. If the reanalysis does not solve the problem (i.e., surrogate compound recoveries are outside the limits for both analyses), the laboratory is required to submit data from both analyses. An independent review is required to determine which is the appropriate sample result.

Secondary Dilutions. When the concentration of any analyte in any sample exceeds the initial calibration range, a new aliquot of that sample must be diluted and reanalyzed. The laboratory is required to report data from both analyses. When this occurs, an independent review of the data is required to determine the appropriate results to be used for that sample. An evaluation of each analyte exceeding the calibration range must be made, including a review of the dilution analysis performed. Results chosen in this situation may be a combination of both the original results (i.e., analytes within initial calibration range) and the secondary dilution results.

Laboratory Control Samples. The laboratory control sample (LCS) serves as a monitor of the overall performance of the analytical process, including sample preparation, for a given set of samples. Evaluation of this standard provides confidence in or allows qualification of results based

on a measurement of process control during each sample analysis. LCS analysis should fall within $\pm 15 \%$ of the mean for the measurement process.

Duplicate Analysis. Both field and laboratory duplicate samples will be evaluated. Field duplicate samples will be collected and containerized from co-located samples during sampling operations. Laboratory duplicates are identical splits of individual samples that are analyzed by the laboratory to evaluate analytical reproducibility and sample homogeneity. These samples are split in the laboratory during sample preparation. A field duplicate will be collected from each ECU, while 1 laboratory duplicate will be performed per 20 samples of similar matrix. The precision goal for mercury in field duplicates is an RPD $<30 \%$ or an absolute difference of $3 \times$ the detection level for values $<10 \times$ the detection level. The precision goal for laboratory duplicates is an RPD $<20 \%$ or an absolute difference of $2 \times$ the detection level for values $<5 \times$ the detection level. 
Matrix Spike Analysis. A matrix spike (MS) is an aliquot of a sample spiked with a known quantity of analyte and subjected to the entire analytical procedure. It is used to indicate the appropriateness of the method for the matrix by measuring recovery. This measurement will provide an indication of the potential sample matrix effect on the sample quantification.

\subsubsection{Data Reporting}

Field data and on-site laboratory data will be recorded in field logbooks, collated into data tables, and reported both in interim progress reports and in the final Remedial Action Report. On-site laboratory data will also be reported on individual ECU sample report forms for immediate evaluation for remediation criteria.

Off-site laboratory confirmation analysis will provide comprehensive data deliverables as identified in Table 2.3.

Table 2.3. Data set deliverables for summary and comprehensive documentation

\begin{tabular}{|c|c|}
\hline Method requirements & Deliverables \\
\hline Holding time information and methods requested & Signed chain-of-custody forms \\
\hline Discussion of laboratory problems & Case narratives \\
\hline $\begin{array}{l}\text { LCS with results on control charts (run with each batch of } \\
\text { samples processed) }\end{array}$ & Control charts \\
\hline Sample results & CLP Form 1 or equivalent \\
\hline Initial and continuing calibration & CLP Form 2 or equivalent \\
\hline $\begin{array}{l}\text { Method blank taken through digestion ( } 1 \text { per } 20 \text { samples of } \\
\text { same matrix) }\end{array}$ & CLP Form 3 or equivalent \\
\hline ICP interference check sample & CLP Form 4 or equivalent \\
\hline Spike sample recovery ( 1 per 20 samples of similar matrix) & CLP Form 5A or equivalent \\
\hline $\begin{array}{l}\text { Postdigestion spike sample recovery for ICP metals (only } \\
\text { done if predigest spike recovery exceeds CLP limits) }\end{array}$ & CLP Form $5 B$ or equivalent \\
\hline Postdigestion spike for graphite furnace atomic absorption & Recovery noted on raw data \\
\hline $\begin{array}{l}\text { Duplicates ( } 1 \text { per } 20 \text { samples will be split and digested as } \\
\text { separate samples) }\end{array}$ & CLP Form 6 or equivalent \\
\hline LCS & CLP Form 7 or equivalent \\
\hline $\begin{array}{l}\text { Standard addition - the decision process outlined in CLP will } \\
\text { be used to determine when standard additions are required }\end{array}$ & CLP Form 8 or equivalent \\
\hline Holding times & CLP Form 10 or equivalent \\
\hline $\begin{array}{l}\text { Complete copy of all laboratory raw data information [bench } \\
\text { notes, computer printouts, etc. (comprehensive documentation)] }\end{array}$ & Raw data \\
\hline $\begin{array}{ll}\text { CLP }= & \text { Contract Laboratory Procedure } \\
\text { ICP }= & \text { Inductively-coupled plasma } \\
\text { LCS }= & \text { laboratory control sample }\end{array}$ & \\
\hline
\end{tabular}




\subsection{INTERNAL QUALITY CONTROL}

\subsubsection{Field Quality Control Samples}

Field blanks are samples of site source water used for the decontamination of sampling equipment. One field blank consisting of the potable water used during the investigation will be collected for mercury analysis. Another field blank of the ASTM Type II water used will not be collected and analyzed.

Equipment rinsate samples are used as a measure of the effectiveness of the decontamination process. For this investigation, one equipment rinsate will be collected by pouring ASTM Type II water through or over one complete set of decontaminated sampling equipment. The equipment rinsate sample will be analyzed for mercury. One equipment rinsate will be collected for each ECU.

One field duplicate sample will be collected and analyzed from each ECU to assess the precision of sampling. The sample will be composed of a split of one of the composited samples. The duplicate sample will be analyzed for the same parameters as the environmental sample collected at that location.

\subsubsection{Laboratory Quality Control}

On-site laboratory QC will include analysis of method blanks, sample duplicates, and LCSs at a frequency of 1 per 20 samples analyzed. Off-site laboratory QC will include analysis of method blanks, sample duplicates, and LCSs, and matrix spikes at a frequency of 1 per 20 samples analyzed.

\subsection{ASSESSMENTS}

The objective of assessments is to (1) verify that the QA program developed for this project is being implemented according to the specified requirements, (2) assess the effectiveness of the QA program, (3) identify nonconformances/variances, and (4) verify that identified deficiencies are corrected.

\subsubsection{Audits}

No audits are presently scheduled for this investigation.

\subsubsection{Surveillances}

Surveillance activities include the monitoring and inspecting of documents and work activities. Surveillances provide a real-time means of evaluating the adequacy and effectiveness of methods for achieving quality and for assessing the quality of final results. Surveillances for this project may be performed by DOE-OR, LMES, MK-Ferguson, JEG, or SAIC personnel. Surveillances conducted by SAIC will be performed in accordance with SAIC QAAPs 18.1, 18.2, and 18.3. The SAIC QA/QC Officer will determine the scope and schedule for each surveillance performed by SAIC. A minimum of one field sampling surveillance and one on-site laboratory surveillance will performed by SAIC for this investigation. Nonconformances will be reported to the DOE ER Project Manager who will determine if the severity requires notifying TDEC and EPA. 


\subsubsection{Project Data Quality Assessment}

The data quality indicator PARCC parameters will be used to evaluate data quality and quantity. Reviewers are responsible for ensuring that data reduction calculations follow appropriate data calculation procedures, are documented, and are checked by qualified personnel.

Both qualitative and quantitative criteria are used as indicators of the quality of the data. In determining data usability, especially in the decision-making process the integrity and authenticity of the data must be evaluated and the analytical uncertainty must be determined. Parameters used to assess data quality for this investigation are precision, accuracy, representativeness, comparability, completeness, and sensitivity. These parameters will be evaluated for all project data.

The following procedures will be used to assess data precision, accuracy, and completeness. These equations apply to both field and laboratory measurements.

\subsubsection{Precision}

Precision is defined as the reproducibility or degree of agreement between duplicate measurements under a given set of conditions. The closer the measurements approach each other, the more precise the measurement. The level of precision is determined by calculating the RPD between the two measurements using the equation below. Precision is determined using either duplicates or LCS analytes.

$$
R P D=\frac{|S-D|}{(S+D) / 2} \times 100 \%
$$

where:

$S=$ analyte concentration of the original sample,

$\mathrm{D}=$ analyte concentration of the duplicate sample.

\subsubsection{Accuracy}

Accuracy is defined as the degree of difference between measured values and the true values. Sampling accuracy will be maximized by adhering to the QAPjP. All procedures used will be documented as standard operating procedures. Analytical measurement accuracy is evaluated through implementation of analyte matrix spike or standard reference material determinations. The following equation will be used to calculate percent recovery (\%R):

$$
\% R=\frac{A-A_{0}}{A_{f}} \times 100 \%
$$

where:
$A_{t}=$ total compound or element concentration detected in the spiked sample,

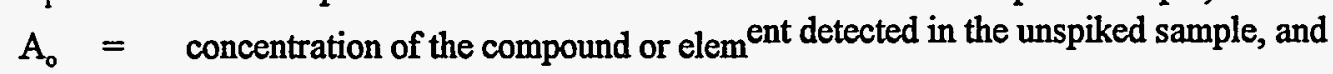
$A_{f}=$ concentration of the compound or element added to the sample. 
For situations in which a standard reference material (SRM) is used rather than or in addition to MS analyses, the following equation will be used:

$$
\% R=\frac{C_{m}}{C_{s m}} \times 100 \%
$$

where:

$$
\begin{aligned}
& C_{m}=\text { measured concentrate of SRM, } \\
& C_{\text {srm }}=\text { actual concen }
\end{aligned}
$$

\subsubsection{Representativeness}

Representativeness expresses the relative degree to which the data depict the characteristics of a population, parameter, sampling point, process condition, or environmental condition. The objective of this study is to accurately represent the chemical concentrations of target analytes in the specified ECU.

Representative samples for this investigation will be acquired through implementation of approved sampling and analytical procedures that will generate data representative of the sample population. Sampling procedures are designed to minimally impact the sample obtained, so that conditions representative of the sampling location will be maintained. Analytical methods will be selected that most accurately represent the true concentration of the parameter of interest. The accumulation of QC procedures and information (i.e., RPD values, blank QC concentrations, MS percent recoveries, etc.) employed for a given analysis combine to exhibit the representativeness of the data generated. The goal for representative sample data will therefore be met through the proper documentation of field and analytical protocols.

\subsubsection{Completeness}

Completeness is the measure of the amount of data obtained from a measurement process that achieves the project goals compared to the amount of data planned to be obtained by the project.

The following are three measures of completeness determined for this investigation.

Sample Collection:

$$
\text { Completeness }=\frac{\text { Number of Sample Points Sampled }}{\text { Number of Sample Points Planned }} \times 100 \%
$$

Field Measurements:

$$
\text { Completeness }=\frac{\text { Number of Valid Field Measurements Made }}{\text { Number of Field Measurements Planned }} \times 100 \%
$$

Laboratory Analysis:

$$
\text { Completeness }=\frac{\text { Number of Valid Laboratory Measurements Made }}{\text { Number of Laboratory Measurements Planned }} \times 100 \%
$$


Completeness goals established for this project for sample collection and field measurements are $95 \%$. If these goals are not met, the necessity for resampling will be determined on a case-by-case basis. The completeness goal for laboratory analysis for this project is also $95 \%$.

\subsubsection{Comparability}

Comparability expresses the confidence with which one data set can be compared with another. Comparability of the data generated in this investigation will be obtained through the implementation of the identified protocols for sampling and analysis of samples. Use of traceable reference materials as laboratory standards, expression of results in standard concentration units, and successful participation by the laboratories in external performance evaluation programs will enable the data produced through this investigation to be compared with further data sets, if required.

\subsection{PREVENTIVE MAINTENANCE PROCEDURES AND SCHEDULES}

\subsubsection{Sampling and Screening Equipment}

Preventive maintenance of hand-operated sampling equipment used in this project is not required. Sufficient spare sampling equipment will be carried to complete the investigation, in the event that tools are broken. A spare mercury vapor analyzer will be held in reserve in case the primary instrument malfunctions. As a minimum, equipment and instruments will be checked daily and taken out of service if found deficient.

\subsubsection{Analytical Instruments}

Preventive maintenance of analytical instruments used for this project will be performed according to the procedures and schedules set forth in the manufacturer's maintenance manuals and as described in appropriate parts of the referenced analytical methods. Specific off-site analytical laboratory maintenance procedures will be in accordance with its QA program.

\subsection{CORRECTIVE ACTION PROCEDURES}

LMES corrective actions to audit/surveillance findings and nonconformances will be managed in accordance with ESS-QA-16.0, 16.1, 16.2 16.3, 16.4, and ESS-QA-15.0 and 15.1. SAIC corrective actions to audit/surveillance findings and nonconformances will be managed in accordance with SAIC QAAPs 15.1 and 16.1. The ER Project Manager will be notified when an NCR is documented and will be furnished a copy as soon as possible. Copies of NCRs and their dispositions will be forwarded to the ER Project Manager for placement in the records center and for reporting to LMES Action Management System (ESAMS), as appropriate. NCRs issued as a result of an audit or surveillance finding will identify the root cause of the problem.

\subsection{QA REPORTS TO MANAGEMENT}

Monthly project status reports will include the following information:

- assessments of measurement data accuracy, precision, and completeness as applicable;

- results of any performance or systems audits or surveillances;

- any significant QA problems and recommended solutions. 
The SAIC Project Manager is responsible for preparing these monthly reports. The Preliminary Assessment/Site Investigation report will include a separate QA section which summarizes data quality information.

\subsection{QA RECORDS}

QA records concerning the project (e.g., internal and external correspondence, work plans, field logbooks and forms, chain-of-custody forms, data packages, audit reports, surveillance reports, NCRs, corrective action reports, etc.) will be submitted to the SAIC Central Records Facility for dual storage and retrieval. Records concerning the project will be forwarded to the ER Project Manager for placement in the ER Document Center during the project. A complete copy of the project file will be submitted to the ER Project Manager at the end of the period of performance for the sampling phase of the project. 


\section{SAIC SITE AND TASK SPECIFIC HEALTH AND SAFETY PLAN FOR CONFIRMATORY SOIL SAMPLING}

\subsection{SITE HEALTH AND SAFETY PERSONNEL}

The Lower EFPC remedial action will be managed by MK-Ferguson personnel. MK-Ferguson, responsible for overall site control and site safety, will provide the overall site HASP and the Site Health and Safety Officer (SHSO). SAIC will not control the site and SAIC on-site personnel will have no health and safety responsibilities other than performing their work safely and complying with this document and with the applicable portions of the MK-Ferguson site HASP. This section outlines the responsibilities of the SAIC sampling team in performance of the confirmatory sampling activity.

\subsubsection{SAIC Project Manager}

The SAIC Project Manager (Greg Schank) is responsible for overall execution of SAIC's responsibilities on this project. Specific responsibilities include:

- coordinating with LMES and MK-Ferguson staff and

- ensuring that SAIC field work is performed in a safe manner and that field personnel comply with the MK-Ferguson and SAIC HASPs.

\subsubsection{SAIC Health and Safety Manager}

The SAIC Health and Safety Manager (Steve Davis, CIH, CSP) is responsible for the SAIC health and safety program. Specific responsibilities include:

- coordinating with MK-Ferguson and LMES Health and Safety personnel and

- reviewing and approving SAIC health and safety plans and changes to those plans.

\subsubsection{Field Project Personnel}

Project personnel involved in on-site operations are responsible for:

- performing only those tasks that they believe they can do safely,

- notifying the SHSO of any medical conditions (e.g., allergies, diabetes, pregnancy) that require special consideration,

- $\quad$ reporting all symptoms of exposure to chemical and physical hazards to the SHSO and SAIC management, and

- abiding by a buddy system so that each on-site worker is responsible for keeping track of his or her partner in the event of an incident. 


\subsection{SAFETY RISK ANALYSIS}

MK-Ferguson, the remedial contractor, is responsible for the assessment and control of sitewide hazards. This responsibility includes the production and enforcement of a site-wide HASP that addresses the entire project. The SAIC plan presented herein is a second tier document subject to the requirements of the MK-Ferguson HASP. The hazard analyses and controls presented in this document are specific to the tasks to be performed by SAIC personnel. Should there be a conflict between the site-wide MK-Ferguson HASP and the SAIC task-specific requirements, the more protective will apply. The scheduled tasks include:

- confirmatory soil sampling to be conducted in 16-in. deep excavations using a JMC Backsaver Soil Sampler after the excavations are complete, and

- on-site analysis of soil samples for mercury concentration using the Static Headspace Analysis for Mercury in Soils (developed at Oak Ridge National Laboratory) (beta test version of method last revised 7/7/95).

These tasks pose a potential for exposure to mercury, analytical reagents, and contact with heavy equipment. The potential for overexposure to mercury during sampling appears to be very low. The potential for overexposure to analytical reagents is more significant and will require more stringent controls. The potential for contact with moving equipment is low because SAIC personnel will not be involved with excavation and will not enter excavations during excavation. Table 3.1 summarizes the hazards and control measures for each site task. Table 3.2 lists expected site contaminants. Hazardous chemicals used in site activities also appear in the table. 
Table 3.1. Hazards analysis

\begin{tabular}{|c|c|c|c|}
\hline Safety and health hazards & Controls & Monitoring & Probability \\
\hline \multicolumn{4}{|c|}{ Surface soil sampling in 16-in. deep excavations } \\
\hline $\begin{array}{l}\text { General soil sampling } \\
\text { hazards (heavy equipment, } \\
\text { slips, falls) }\end{array}$ & $\begin{array}{l}\text { No excavation entry during excavation } \\
\text { PPE (level D) Minimum for task is: } \\
\text { Hard hat (if overhead hazards are present) } \\
\text { Safety glasses with side shields } \\
\text { Safety boots } \\
\text { Field work clothes }\end{array}$ & & Low \\
\hline $\begin{array}{l}\text { Exposure to chemicals } \\
\text { (see Table 3.2) }\end{array}$ & $\begin{array}{l}\text { Nitrile or similar gloves for handling potentially contaminated materials } \\
\text { Minimal contact }\end{array}$ & $\begin{array}{l}\text { Performed by } \\
\text { MK-Ferguson }\end{array}$ & Low \\
\hline $\begin{array}{l}\text { Animal hazards (bees, } \\
\text { ticks, wasps, snakes) }\end{array}$ & $\begin{array}{l}\text { PPE (boots, work clothes) } \\
\text { Insect repellant if necessary }\end{array}$ & Visual survey & Low \\
\hline Temperature extremes & Administrative controls to include rest breaks and adequate fluid replacement & & $\begin{array}{l}\text { Varies by } \\
\text { season }\end{array}$ \\
\hline \multicolumn{4}{|c|}{ Soil sample analysis in on-site laboratory } \\
\hline $\begin{array}{l}\text { General safety hazards } \\
\text { (slips, cuts) }\end{array}$ & $\begin{array}{l}\text { Good housekeeping, clean up spills immediately, use plastic containers when possible, } \\
\text { adequate lighting }\end{array}$ & & Low \\
\hline $\begin{array}{l}\text { Exposure to chemicals } \\
\text { (see Table } 3.2 \text { ) }\end{array}$ & $\begin{array}{l}\text { Establish segregated work area for screening; follow established analytical procedure; } \\
\text { maintain Material Safety Data Sheets in the work area; hazard labels on all chemicals; } \\
\text { exclude unnecessary personnel; no eating, drinking, food storage or unrelated work in } \\
\text { screening area; wash hands and face prior to taking anything by mouth; clean work } \\
\text { surface at least daily; use plastic backed sorbent paper or similar material to cover the } \\
\text { work surface and change this material when it becomes contaminated and at least daily; } \\
\text { wear laboratory gloves, goggles, and lab coat or similar garment; remove any clothing } \\
\text { (including gloves) that becomes soiled with sample or reagents; keep spill and } \\
\text { neutralization kit immediately available; clean up spills immediately; keep 15-minute } \\
\text { eyewash immediately available; provide mechanical exhaust ventilation and perform } \\
\text { reagent preparation and similar procedures inside or immediately in front of the exhaust } \\
\text { intake; operate mechanical exhaust continuously during chemical handling; store } \\
\text { chemicals and wastes in sealed containers inside secondary containment. }\end{array}$ & & Moderate \\
\hline
\end{tabular}


Table 3.2. Potential exposures

\begin{tabular}{|c|c|c|c|c|}
\hline Chemical $^{a}$ & TLV/PEL/DLH ${ }^{s}$ & $\begin{array}{c}\text { Health effects/ } \\
\text { potential hazards }^{c}\end{array}$ & Chemical and physical properties $^{c}$ & $\begin{array}{l}\text { Exposure } \\
\text { route(s) }\end{array}$ \\
\hline $\begin{array}{l}\text { Bromine monochloride } \\
\text { solution (used in on-site } \\
\text { analysis) }\end{array}$ & $\begin{array}{l}\text { TLV/PEL: } 0.1 \mathrm{ppm} \text { as } \\
\text { bromine, } \mathrm{C} 5 \mathrm{ppm} \text { as } \\
\text { hydrochloric acid }\end{array}$ & $\begin{array}{l}\text { Corrosive; irritation of eyes, skin, } \\
\text { mucous membranes; dizziness; } \\
\text { headache }\end{array}$ & Liquid with irritating odor; FP: none & $\begin{array}{l}\text { Inhalation } \\
\text { Ingestion } \\
\text { Contact }\end{array}$ \\
\hline $\begin{array}{l}\text { Hydrochloric acid (used } \\
\text { in on-site analysis) }\end{array}$ & $\begin{array}{l}\text { TLV/TWA: C5 ppm } \\
\text { IDLH: } 50 \text { ppm }\end{array}$ & $\begin{array}{l}\text { Irritation of eyes, skin, mucous } \\
\text { membranes; choking }\end{array}$ & $\begin{array}{l}\text { Liquid with pungent irritating odor; } \\
\text { FP: NA; IP: } 12.74 \mathrm{eV}\end{array}$ & $\begin{array}{l}\text { Inhalation } \\
\text { Ingestion } \\
\text { Contact }\end{array}$ \\
\hline $\begin{array}{l}\text { Mercury (site } \\
\text { contaminant and } \\
\text { analytical standard) }\end{array}$ & $\begin{array}{l}\text { TLV/TWA: } 0.025 \\
\text { A4 mg/m }\end{array}$ & $\begin{array}{l}\text { Irritation of eyes; chest pain; } \\
\text { tremors; headache }\end{array}$ & $\begin{array}{l}\text { Silver liquid; VP: } 0.0012 \mathrm{~mm} \text {; } \\
\text { FP: none }\end{array}$ & $\begin{array}{l}\text { Inhalation } \\
\text { Ingestion } \\
\text { Absorption } \\
\text { Contact }\end{array}$ \\
\hline $\begin{array}{l}\text { Nitric acid (used in on- } \\
\text { site analysis) }\end{array}$ & $\begin{array}{l}\text { TLV/TWA: } 2 \text { ppm } \\
\text { DLH: } 25 \text { ppm }\end{array}$ & $\begin{array}{l}\text { Corrosive; Irritation of eyes, nose, } \\
\text { throat; delayed pulmonary edema; } \\
\text { may increase the combustibility of } \\
\text { organic materials; generates heat } \\
\text { in contact with water }\end{array}$ & $\begin{array}{l}\text { Liquid with acrid suffocating odor; } \\
\text { VP: } 48 \mathrm{~mm} \text {; FP: NA; IP: } 11.85 \mathrm{eV}\end{array}$ & $\begin{array}{l}\text { Inhalation } \\
\text { Ingestion } \\
\text { Contact }\end{array}$ \\
\hline $\begin{array}{l}\text { Stannous chloride } \\
\text { solution (used in on-site } \\
\text { analysis) }\end{array}$ & $\begin{array}{l}\text { TLV/PEL: } 2 \mathrm{mg} / \mathrm{m}^{3} \text { as tin } \\
\text { IDLH: } 100 \mathrm{mg} / \mathrm{m}^{3} \text { as tin }\end{array}$ & $\begin{array}{l}\text { Somewhat corrosive; irritation of } \\
\text { eyes, skin, respiratory system; } \\
\text { gastrointestinal tract distress }\end{array}$ & $\begin{array}{l}\text { Liquid solution containing stannous } \\
\text { chloride, hydrochloric acid, and water; } \\
\text { FP: none }\end{array}$ & $\begin{array}{l}\text { Inhalation } \\
\text { Ingestion } \\
\text { Contact }\end{array}$ \\
\hline
\end{tabular}

a The chemicals were obtained from the Lower East Fork Remedial Investigation report and Static Headspace Analysis for Mercury in Soils (developed at Oak Ridge National Laboratory) (beta test version of method last revised 7/7/95).

- From 1995-1996 Threshold Limit Values, NIOSH Pocket Guide to Chemical Hazards:

c From 1994 NIOSH Pocket Guide to Chemical Hazards.

$\mathrm{C}=$ ceiling limit

$\mathrm{FP}=$ flash point

IDLH $=$ immediately dangerous to life and health

IP = ionization potentia
NA = not available

$\mathrm{NIOSH}=$ National Institute of

Occupational Safety and Health

PEL = permissible exposure limit
TLV $=$ threshold limit value

TWA = time-weighted average

$\mathrm{VP}=$ vapor pressure 


\subsection{TRAINING REQUIREMENTS}

SAIC personnel who perform these and any other on-site tasks are subject to the following training requirements listed in Table 3.3. Note that these requirements are the minimum and that the MK-Ferguson HASP may include additional training requirements.

Table 3.3. Training requirements

\begin{tabular}{lcc}
\multicolumn{1}{c}{ Training } & Worker & Supervisor \\
\hline OSHA (40 h, 3 day OJT) & $\checkmark$ & $\checkmark$ \\
OSHA Annual Refresher (8 h) & $\checkmark$ & $\checkmark$ \\
OSHA Supervisors Training (8 h) & $\times$ & $\checkmark$ \\
General Hazard Communication Training & $\checkmark$ & $\checkmark$ \\
(contained in 40 h) & & \\
Respiratory Protection & $\checkmark$ & $\checkmark$ \\
(required only if respirators & & \\
are worn; contained in 40 h) & & $\checkmark$ \\
Site Access Briefing (conducted by MK-Ferguson) & $\checkmark$ & $\checkmark$ \\
Site Specific Hazard Communication (conducted by & $\checkmark$ & $\checkmark$ \\
MK-Ferguson) & & \\
Safety Briefing (conducted by MK-Ferguson) & $\checkmark$ & \\
\hline
\end{tabular}

OJT = On-the-job training

OSHA $=$ Occupational Safety and Health Administration

$\sqrt{ }=$ Required

$x \quad=$ Not required 


\subsection{PERSONAL PROTECTIVE EQUIPMENT}

Personal protective equipment (PPE) for general site activities will be specified in the MK-Ferguson HASP. SAIC will utilize at least Level D PPE. If a conflict exists between this document and the MK-Ferguson HASP, the more restrictive will apply. This section emphasizes the programmatic requirements for PPE. Levels of protection that may be used to protect against chemical and physical hazards at this site include:

- Level D+ Protective Equipment

- coated Tyvek@ coveralls

- chemical-resistant disposable gloves

- safety boots

- hard hat (if overhead hazards are present)

- safety glasses

- Level D Protective Equipment

- coveralls/field clothes

- safety boots

- safety glasses with side shields

- hard hat (if overhead hazards are present)

If site conditions indicate that other levels of PPE will be required, the SAIC Health and Safety Manager will be contacted by the SAIC on-site personnel for consultation.

\subsection{MEDICAL SURVEILLANCE}

Employees performing hazardous waste related work may be exposed to hazardous chemicals, various forms of radiation, noise hazards, biological hazards, and safety hazards. SAIC employees performing on-site work as part of this project will, as a minimum, be enrolled in a medical surveillance program to comply with 29 CFR 1910.120.

\subsection{MONITORING AND SAMPLING}

MK-Ferguson, as the remedial contractor, will be responsible to conduct exposure assessment to verify that on-site personnel are not overexposed to site contaminants. SAIC personnel will comply with any monitoring requirements prescribed by the MK-Ferguson Health and Safety staff.

\subsection{SITE CONTROL MEASURES}

The remedial contractor, MK-Ferguson, will be responsible for establishing the site control zones, as necessary, around areas that present physical, chemical, and/or radiological hazards. SAIC personnel will comply with the site control zones established by the MK-Ferguson Health and Safety staff. 


\subsection{DECONTAMINATION PROCEDURES}

MK-Ferguson, the remedial contractor, is responsible for establishing decontamination procedures, as necessary, to protect on-site personnel from adverse effects due to contamination. As a minimum, SAIC personnel will wash hands and faces upon leaving any contaminated area, handling potentially contaminated/hazardous material, and prior to taking anything by mouth.

\subsection{SITE OPERATING PROCEDURES}

This section presents those general safety rules that apply to SAIC activities conducted as part of this project:

- SAIC personnel will attend MK-Ferguson "Tailgate" safety meetings.

- Contact with potentially contaminated substances will be avoided. Site personnel in the exclusion zone will attempt to avoid walking through puddles, pools, or mud, kneeling on the ground, and leaning or sitting on equipment or the ground. Site personnel will not place monitoring equipment on a potentially contaminated surface.

- All injuries will be reported to the MK-Ferguson SHSO and SAIC management.

- All on-site workers will abide by a buddy system. Members of a buddy team will maintain verbal or visual contact while in the exclusion zone. Note that frequent radio contact or interaction with nearby MK-Ferguson personnel will satisfy this requirement.

- Copies of Manufacturers' Safety Data Sheets for all hazardous chemicals (chemicals brought on site) will be maintained in the work area and made available to the MK-Ferguson SHSO.

- All containers of hazardous chemicals with be labeled to comply with the requirements of 29 CFR 1910.1200, the Hazard Communication standard.

\subsection{CONTINGENCY PLAN}

The remedial contractor, MK-Ferguson, is responsible to develop contingency plans to address potential site emergencies. SAIC personnel will comply with the requirements of these plans. SAIC personnel will become familiar with site contingency plans by attending MK-Ferguson on-site training. As a minimum, the SAIC personnel will be supplied with the following emergency equipment:

- first aid kit suitable to treat minor injuries such as cuts and abrasions,

- fifteen minute eye wash when corrosive materials are poured,

- telephone, and

- basic spill kit suitable to handle small spills of analytical reagents. 


\section{REFERENCES}

Kimbrough et al. 1990. Environmental Surveillance Procedures Quality Control Program, ES/ESH/INT-4.

Kriger, A.A. and R.R. Turner 1996. In press, Water, Air and Soil Pollution.

NIOSH (National Institute for Occupational Safety and Health) 1994. Pocket Guide to Chemical Hazards, U.S. Department of Health and Human Services, Public Health Service, Centers for Disease Control, June. 
Appendix

STATIC HEADSPACE ANALYSIS FOR MERCURY IN SOILS 


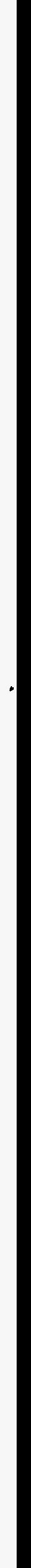




\section{Static Headspace Analysis for Mercury in Soils (Developed at Oak Ridge National Laboratory) [Revision 1.1, 10/22/95]}

\subsection{Scope and Application}

This is a field screening method for the rapid determination of mercury concentration in soils. Soil samples are first digested (oxidized and extracted) with aqua regia and then an aliquot of the digest is transferred to another container for chemical reduction and analysis of the mercury vapor in the sample headspace. While this method has a detection limit comparable to typical laboratory methods employing cold vapor atomic absorption, it is not intended to be an alternate to formal laboratory methods. However, when carefully applied the method is fully capable of producing results comparable to laboratory methods. The method requires a portable mercury vapor analyzer and the description given here assumes use of a Jerome Model 431-X Mercury Vapor Analyzer (manufactured by Arizona Instrument Inc., Phoenix, AZ, and widely available in the hazmat equipment rental market). Other portable detectors may also function satisfactorily but this method has not been tested nor optimized for any other detector. Applications include field selection of soil/sediment samples for formal laboratory analysis, rapid field definition of the areal and depth boundaries of mercury contamination in soil, and rapid field guidance of cleanup activities, including verification sampling.

\subsection{Summary of Method}

A 0.20 - to $0.40-\mathrm{g}$ sample of homogenized soil is extracted with $8 \mathrm{~mL}$ of an acid mixture, aqua regia (three parts concentrated hydrochloric acid and one part concentrated nitric acid) in a 40$\mathrm{mL}$ glass bottle with Teflon-lined silicone septum cap. The glass bottles are left loosely capped to vent any gas pressure created during digestion (which requires a minimum of $15 \mathrm{~min}$ ). A $0.01-\mathrm{mL}$ to $1.0-\mathrm{mL}$ aliquot of the well-mixed diluted extract is transferred to a 1-L polyethylene bottle containing $100 \mathrm{~mL}$ of deionized water. A 5-mL aliquot of a saturated stannous chloride $\left(\mathrm{SnCl}_{2}\right)$ solution is added to the sample. The bottle is capped and vigorously shaken manually for $1 \mathrm{~min}$. The cap is removed and a square of parafilm is quickly stretched over the bottle opening. The parafilm seal is punctured using a special probe tip fitted to a portable mercury vapor analyzer. A sample of the headspace gas is taken with a mercury vapor analyzer and the results recorded.

Quantitative results can be obtained in the range of 0.1 to $14 \mu \mathrm{g} / \mathrm{L}$ in the diluted extract. Method detection limit for soil depends largely on the extract aliquot size transferred for reduction and analysis. For example, the method detection limit for a 0.2-gram soil sample, with a total extract volume of $23 \mathrm{~mL}$ and a transferred extract volume of $1.0 \mathrm{~mL}$, would be approximately $1 \mu \mathrm{g} / \mathrm{g}$. Lower detection limits for soil can be achieved by digesting larger samples and/or by increasing the extract aliquot volume transferred for analysis. Use of the smallest aliquot size transferred (e.g., $0.01 \mathrm{~mL}$ ) or extract dilution can bring even very high mercury concentrations in soil extracts within the operating range of the method. See Kriger and Turner (1995) for additional information about method development. 


\subsection{Interferences}

This method is relatively free of interferences due to separation of mercury from other nonvolatile constituents of soil and the high selectivity of the Jerome mercury vapor analyzer. However, there are some potential interferants. Iodine compounds (iodides, iodates) are known to suppress the reduction of mercury by stannous chloride. Fortunately, soils do not ordinarily contain enough iodide to cause any detectable interference. Free halogens, especially iodine and bromine, are not always effectively removed by the soda lime traps and may cause a positive response on the analyzer. While the addition of $\mathrm{SnCl}_{2}$, in great excess beyond that necessary to reduce mercury, is intended to assure complete reduction of any free halogens, on rare occasions these may survive in the sample headspace if samples are not adequately shaken. Halogen interference is typically characterized by inability to obtain a zero instrument reading (i.e., $<0.001 \mathrm{mg} / \mathrm{m}^{3}$ ) in ambient air. Regeneration of the gold film at this point restores ability to zero and thus proper function. Although unlikely to be encountered in the highly acidic soil digests, unionized ammonia will also cause a false positive reading on the Jerome mercury vapor analyzer. If ambient air in the work area contains ammonia the only recourse is to move to another area. Similarly, high ambient air concentrations of organic sulfur compounds (e.g., mercaptans, volatile thiols) may also produce false positives and difficulty obtaining a zero reading on the Jerome prior to sample headspace measurements. Lastly, the Jerome analyzer should always be operated in a thermally stable environment as sudden temperature changes can greatly affect instrument response. Thus, outdoor areas likely to experience rapid temperature fluctuations (e.g., alternately full sun and shade) should be avoided. Thermal effects are often characterized by wildly varying instrument readings in ambient air otherwise expected or known to be free of elemental mercury.

\subsection{Safety}

Extreme care should be exercised when handling concentrated acids. The use of appropriate gloves, protective clothing and face shields is strongly recommended. The samples should be extracted in a well-ventilated area or fume hood. Caps on the vials should never be tightened until the samples have been diluted. Even after dilution, the soil digests are corrosive and exhibit a strong odor of chlorine. Note that dilution of the concentrated aqua regia with water should be conducted with particular care, as the reaction is slightly exothermic (generates heat).

A soil extraction kit which employs aqua regia has recently become available commercially and is recommended as a safer approach for digesting soils for this procedure. The kit is available from Mercury Science, 4802 Glendarion Dr., Durham, NC 27713, Phone 919/493-0688.

Residual headspace gas in the used 1-L polyethylene analytical bottles will contain mercury vapor even after the spent $\mathrm{SnCl}_{2}$ has been rinsed out. Although this presents a small source of mercury vapor per bottle, many bottles stored in a poorly ventilated or confined space could pose an inhalation hazard. To minimize mercury vapor exposure, the used polyethylene bottles should be recapped tightly and stored in a well-ventilated area pending disposal. Rinsing the bottles with a dilute bleach (sodium hypochlorite) solution will reduce this hazard. In addition, inability to obtain a zero reading $\left(<0.001 \mathrm{mg} / \mathrm{m}^{3}\right)$ on the analyzer between samples should indicate a possible buildup of mercury vapor in ambient air in the work area and should trigger further investigation of the source. 


\subsection{Apparatus and Materials}

5.1 Portable balance capable of weighing to $0.01 \mathrm{~g}$ (e.g., Acculab Pocket Pro C/50).

5.2 Mercury Vapor Analyzer-Jerome Model 431X (Arizona Instrument Inc.) Jerome Model 411 may also be used but is somewhat less sensitive.

5.3 Soda lime trap and probe (See Figure 1)

* Glass wool

* Polyethylene drying tube: Bel-Art Products (6.5 cm in length)

* Soda lime-indicating type (4-8 mesh): J.T. Baker

* Teflon $1 / 4^{\prime \prime}$ tubing and $90^{\circ}$ elbow

* $\quad$ Silicone tubing (3/16" I.D.)

A small quantity of glass wool is placed at both ends of a polyethylene tube (Note that these tubes are cut in half for use). Each tube is filled with soda lime. The trap should be replaced at least daily or as needed. This trap should prevent accidental aspiration of any liquid into the Jerome and serves the redundant function of removing acid gases. The Jerome is equipped with a similar internal trap. Under some circumstances, the external trap may begin to absorb mercury vapor and thus reduce the true signal from the sample. Thus if aqueous standards suggest the calibration is changing, this external trap should be changed immediately and the calibration rechecked.

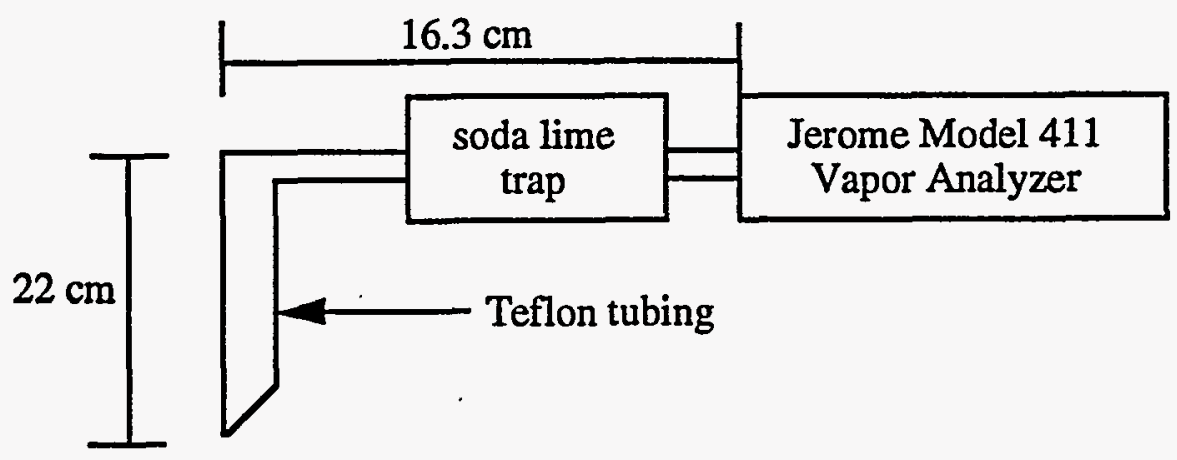

Figure 1. Schematic of probe tip and soda lime trap

5.4 Parafilm (PM-992, 2-inch by 250-foot roll)

5.5 Polyethylene 1-L bottles, small-mouthed: HDPE bottle for the analysis of metals (e.g., I-Chem 313-1000) 
5.6 Gloves, safety glasses, face shield

5.7 Paper towels

5.8 Laboratory tissue

5.9 Liquid waste container

5.10 Pipettors: Eppendorf or similar, 10-100 $\mu \mathrm{L}, 0.1-1.0 \mathrm{~mL}$

5.11 Glass vials with Teflon-lined silicone septum closures ( $40 \mathrm{~mL}$ capacity)

5.12 Graduated cylinder (100 mL capacity)

5.13 Liquid dispenser: Repipet II or similar (0-10 mL capacity)

\subsection{Reagents}

\subsection{Deionized water}

6.2 Hydrochloric acid: concentrated, J.T. Baker or equivalent

6.3 Nitric acid: concentrated, J.T. Baker or equivalent

6.4 Stannous chloride solution: Saturated $\mathrm{SnCl}_{2}$ solution is prepared by dissolving $200.0 \mathrm{~g}$ $\mathrm{SnCl}_{2}$ dihydrate in $100 \mathrm{~mL}$ of $30 \%$ hydrochloric acid and diluting to $1.0 \mathrm{~L}$ with distilled water. The solution was stirred for $24 \mathrm{~h}$ at room temperature while bubbling with "mercury-free" air. The latter procedure is not typically necessary if $\mathrm{SnCl}_{2}$ for $\mathrm{Hg}$ analysis (e.g., J.T. Baker) and a low-Hg-content batch of $\mathrm{HCl}$ are used.

6.5 Bromine monochloride solution: Potassium bromide ( $\mathrm{KBr}$ ), $5.4 \mathrm{~g}$, is dissolved in a 0.5-L bottle of concentrated $\mathrm{HCl}$, stirring for $1 \mathrm{~h}$ in a fume hood. Finally, $7.6 \mathrm{~g}$ of $\mathrm{KBrO}_{3}$ is added while stirring.

6.6 Mercury standards: The assay is linear in the range of 0.1 to $14 \mu \mathrm{g} / \mathrm{L}$. A secondary standard $\left(1.0 \mu \mathrm{g} / \mathrm{mL} \mathrm{Hg} \mathrm{Hg}^{+2}\right)$ is prepared using a NIST traceable mercury standard for atomic absorption $\left(1000 \mu \mathrm{g} / \mathrm{mL} \mathrm{Hg}^{+2}\right)$ or NST SRM $3133(10 \mu \mathrm{g} / \mathrm{mL})$. The secondary standard should be preserved with $5 \mathrm{~mL}$ of bromine monochloride solution. The secondary standard is stable for up to one year. An external calibration curve is constructed by making a series of dilutions of the secondary standard. This is most easily accomplished by dispensing aliquots (e.g., $0.0,0.1,0.2$, $0.5,1.0 \mathrm{~mL}$ ) of the secondary mercury standard into the 1-L analytical bottles which contain 100 $\mathrm{mL}$ of deionized water. Although Jerome readings can be used directly with Henry's Constant to calculate the concentration of mercury in the analyzed aliquot, this practice is not recommended because it relies only on the internal calibration of the Jerome using a gaseous standard. The rectuction and headspace equilibration portions of the complete procedure are thus not taken into consideration. In addition, experience has demonstrated that this internal calibration can drift over time and even over the course of a field anabytical session. Thus, frequent verification of the mercury reduction and detection portion of the complete procedure is recommended. A low aqueous standard of $2.0 \mu \mathrm{gL}(0.2 \mathrm{~mL}$ of the secondary standard $) \mathrm{man}$ after every five to ten samples has proven useful in tracking calibration. 


\subsection{Sample Collection, Preservation, and Handling}

The soil samples should be collected and stored in screw-cap glass or plastic containers. They should be analyzed as soon as possible, but not later than a few days after collection if not preserved by refrigeration $\left(4^{\circ} \mathrm{C}\right)$ or drying $\left(<60^{\circ} \mathrm{C}\right.$ overnight). Mercury contaminated soil samples may be classified as hazardous waste, and the acid extracts will be classified as hazardous when disposal is required. After the addition of $\mathrm{SnCl}_{2}$, the aqueous portion of samples will be considered hazardous waste because of a $\mathrm{pH}$ less than 2 (corrosive under $\mathrm{RCRA}$ ). The waste $\mathrm{SnCl}_{2}$ is collected in a bottle until it can be neutralized, and then it may be discarded into a sanitary sewer under most conditions as non-hazardous waste. Specific regulations governing waste handling and disposal at each site should be consulted prior to disposal. Note that no cost effective means of cleaning the 1-L polyethylene bottles for reuse has been discovered.

\subsection{Procedure}

\subsection{Sample processing, extraction, and headspace vapor measurement}

* A small quantity of soil (e.g. $0.2 \pm 0.01 \mathrm{~g}$ ) is weighed into a $40-\mathrm{mL}$ glass vial with Teflon-lined cap.

* $\quad 6.0 \mathrm{~mL}$ of concentrated $\mathrm{HCl}$ and $2.0 \mathrm{~mL}$ of concentrated $\mathrm{HNO}_{3}$ are dispensed directly into the glass vial. Do not premix these acids.

* After not less than 15 minutes carefully add $15 \mathrm{~mL}$ of distilled water to each sample.

* A 0.01 - to $1.0-\mathrm{mL}$ soil extract aliquot is transferred to a $1-\mathrm{L}$ polyethylene bottle which contains $100 \mathrm{~mL}$ of distilled water. Note that selecting the lowest extract aliquot which gives an instrument response between about 0.010 and $0.100 \mathrm{mg} / \mathrm{m}^{3}$ is desirable to prolong the interval between regenerations of the detector (see Jerome manual for details about regeneration).

* Saturated $\mathrm{SnCl}_{2}$ solution, $5 \mathrm{~mL}$ from a liquid dispenser, is added directly to the sample in the polyethylene bottle.

* The bottle is capped and manually shaken vigorously for $1 \mathrm{~min}$. to assure thorough mixing of the $\mathrm{SnCl}_{2}$ with the sample and to achieve equilibration of mercury vapor between the solution and gas phase.

* A small square ( $2 \times 2$ inch) of parafilm is pressed tightly over the top of the bottle. The parafilm seal reduces the possibility of variable amounts of unequilibrated air entering the bottle while sampling and thus increases precision of replicate measurements.

* The parafilm seal is punctured with the probe tip of the mercury vapor analyzer. Care should be taken not to aspirate liquids into the mercury vapor analyzer.

* The headspace vapor is sampled for one 7-second interval. Note that the Jerome Model 411 uses a 10-second interval and has no purge intervals. 
* The mercury vapor concentration is recorded.

* The probe tip is removed from the bottle, and two or three air samples are taken to zero the instrument before the next sample is analyzed.

8.2 Determination of moisture content in the soil samples: Soil samples can be analyzed even if wet, but results are usually required to be reported on a dry weight basis. Whenever possible, the samples should be dried and homogenized before the analysis (dry homogenization is often more effective than wet). To determine the moisture content of a soil sample, a given amount of wet soil is weighed in a disposable weighing boat, placed in a microwave oven for approximately $7 \mathrm{~min}$, and then weighed again after the sample cools. Note that losses of mercury from samples during drying by microwaves has not been explored and thus this method of drying soils/sediments should not be used except to obtain moisture content of a separate sample. Also, the sample can be dried overnight in a well-ventilated area or fume hood.

8.3 Regeneration of the gold film in analyzer: The Jerome Model $431-\mathrm{X}$ and its predecessor Model 411 must be "regenerated" when the internal gold film reaches a certain level of mercury saturation. This level can be reached rapidly after just a few samples which are high in mercury, necessitating taking the analyzer out of service for about $30 \mathrm{~min}$ while regeneration and thermal restabilization occur. This process requires line voltage (110-130 VAC) for $10 \mathrm{~min}$ after which the unit can be removed from line power if battery charging is not required. Selection of the smallest extract aliquots for analysis will prolong the time between regenerations. Furthermore, it is recommended that two instruments be available and operated alternately if many samples are to be run. A portable generator may be used to regenerate the gold film and recharge the batteries of one unit while the other unit is in service. The manufacturer suggests allowing 20 minutes for thermal stabilization after the regeneration before resuming instrument use. 


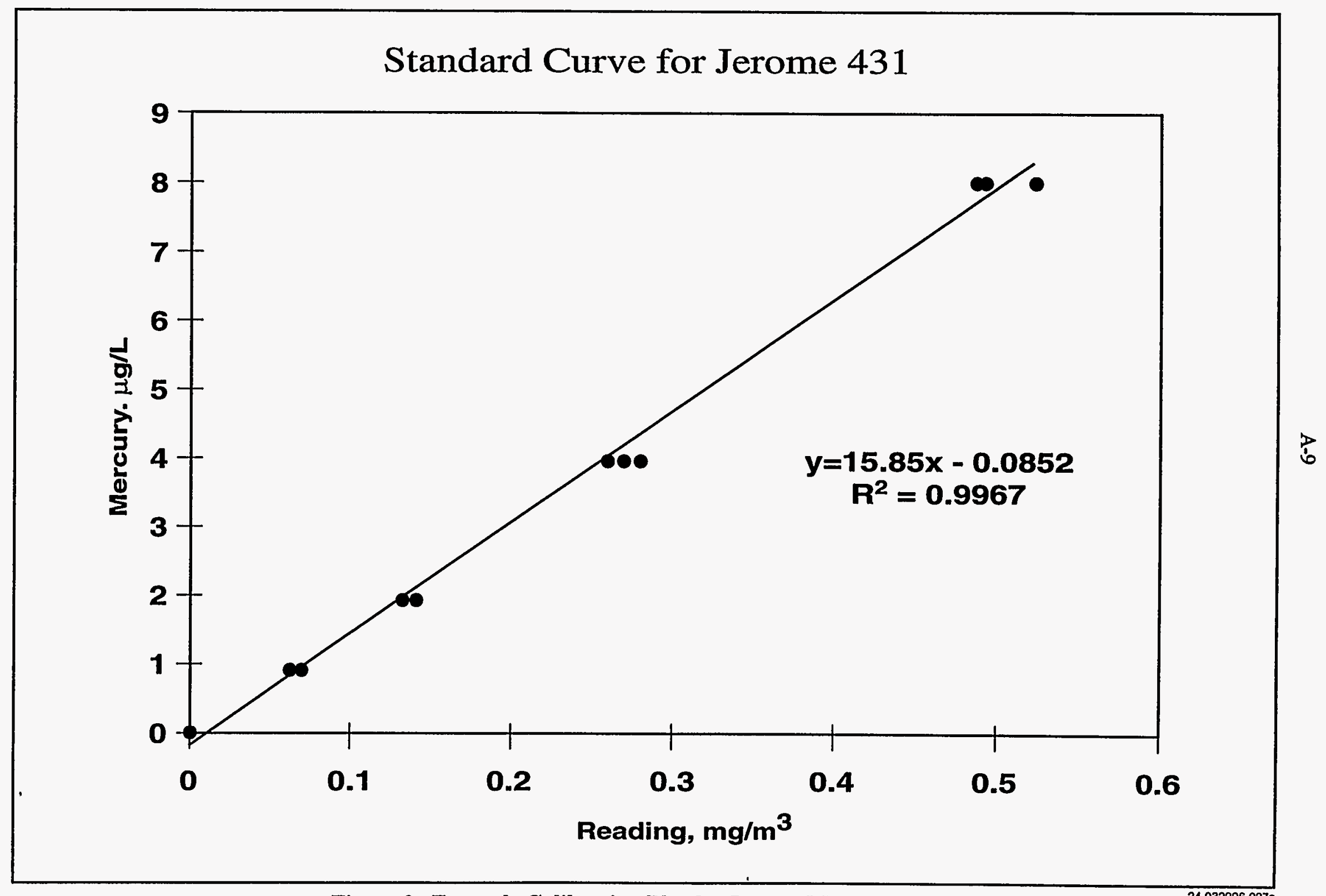

Figure 2. Example Calibration Plot for Jerome Model 431-X

24-032996-027a 


\subsection{Calculations}

9.1 Determination of $\mathbf{H g}$ calibration: A calibration curve is generated by making a plot of the $\mathrm{Hg}$ concentration of the aqueous standards versus the Jerome readings $\left(\mathrm{mg} / \mathrm{m}^{3}\right)$. A calibration blank (distilled water only) should also be included to verify a "zero" response on the analyzer. The slope of the calibration curve can be used as the slope factor (e.g., Figure 2). Multipoint calibration is optional once the analyst has established linearity between aqueous mercury concentrations and instrument readings. When only one standard is used for calibration purposes, the slope factor is calculated as follows:

$$
\begin{aligned}
& \text { Slope factor }\left(\mu \mathrm{g} \mathrm{m}^{3} / \mathrm{mg} \mathrm{L}\right)=\left[\mathrm{V}^{*} \mathrm{C} / \mathrm{T}\right] *\left[1000 \mathrm{mLL}^{-1} / \mathrm{G}\right] \\
& \text { where } \\
& V=\text { volume of standard }(\mathrm{mL}) \\
& \mathrm{C}=\text { concentration of the mercury standard }(\mu \mathrm{g} / \mathrm{mL}) \\
& I=\text { Jerome readings }\left(\mathrm{mg} / \mathrm{m}^{3}\right) \\
& \mathrm{G}=\text { volume of water }(\mathrm{mL})
\end{aligned}
$$

9.2 Determination of $\mathrm{Hg}$ concentration in soil samples: The amount of $\mathrm{Hg}$ in the diluted extract of unknown soil samples is determined by using the formula:

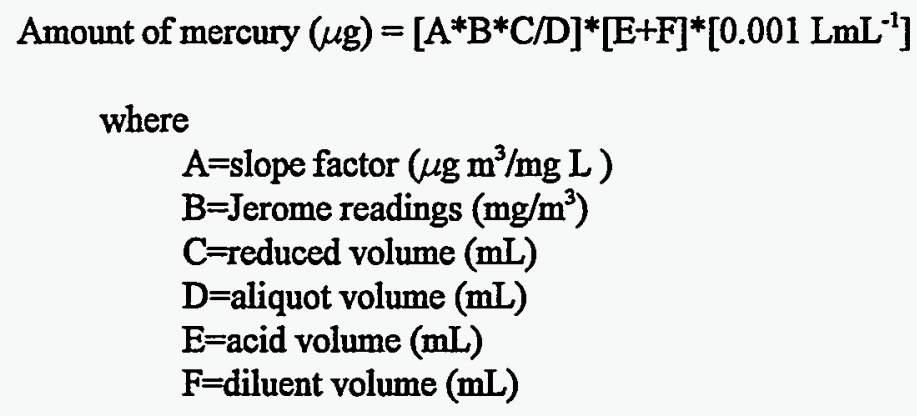

The amount of mercury per weight of soil is obtained as follows:

Amount of dry soil sample $(\mathrm{g})=\left[1-(\% \text { moisture*0.01) }]^{*}\right.$ sample weight of dry soil sample (g)

Amount of $\mathrm{Hg}$ per gram of soil $(\mu \mathrm{g} / \mathrm{g})=$ Amount of mercury $\quad(\mu \mathrm{g}) /$ Amount

A spreadsheet program which contains all the necessary calculations is included as an example on the next page. The program can be used with Lotus, Quattro Pro, or Excel spreadsheet programs. 


\section{Example Spreadsheet and Data for Calculation of Soil Mercury Concentration}

\begin{tabular}{|c|c|c|c|c|c|c|c|c|c|c|c|c|c|}
\hline & $\mathbf{A}$ & B & $\mathbf{C}$ & $\mathbf{D}$ & $\mathbf{E}$ & $\mathbf{F}$ & $\mathbf{G}$ & $\mathbf{H}$ & I & $\mathbf{J}$ & $\mathbf{K}$ & $\mathbf{L}$ & $\mathbf{M}$ \\
\hline 1 & \multicolumn{8}{|c|}{ Project: Jacobs } & \multicolumn{3}{|c|}{ Instrument Serial No: 1782} & & \\
\hline 2 & \multicolumn{13}{|c|}{ Date: May 4-7, 1995} \\
\hline 3 & $\begin{array}{c}\text { Sample } \\
\text { ID }\end{array}$ & $\begin{array}{c}\text { Time } \\
\text { Start } \\
\text { Digestion }\end{array}$ & $\begin{array}{c}\text { Time } \\
\text { Start } \\
\text { Analysis }\end{array}$ & $\begin{array}{c}\text { Moisture } \\
\text { Content }\end{array}$ & $\begin{array}{l}\text { Sample } \\
\text { Weight }\end{array}$ & $\mid \begin{array}{c}\text { Acid } \\
\text { Volume }\end{array}$ & $\begin{array}{l}\text { Diluent } \\
\text { Volume }\end{array}$ & $\begin{array}{c}\text { Transferred } \\
\text { Volume }\end{array}$ & $\begin{array}{c}\text { Reduced } \\
\text { Volume }\end{array}$ & $\begin{array}{l}\text { Jerome } \\
\text { Reading }\end{array}$ & $\begin{array}{c}\text { Slope } \\
\text { Factor }{ }^{*}\end{array}$ & $\begin{array}{c}\text { Field } \\
\text { Mercury }\end{array}$ & \\
\hline 4 & & & & $(\%)$ & (g) & $(\mathrm{mL})$ & $(\mathrm{mL})$ & (mL) & $(\mathrm{mL})$ & $(\mathrm{mg} / \mathrm{m} 3)$ & & $(\mu \mathrm{g} / \mathrm{g})^{\mathrm{b}}$ & Comments \\
\hline 5 & 2701 & $5 / 41930$ & $5 / 51005$ & 0 & 0.24 & 8 & 15 & 0.02 & 100 & 0.015 & 18 & 129 & \\
\hline 6 & 2702 & $5 / 41930$ & $5 / 51025$ & 0 & 0.24 & 8 & 15 & 0.01 & 100 & 0.008 & 18 & 138 & \\
\hline 7 & 2703 & $5 / 41930$ & $5 / 51010$ & 0 & 0.26 & 8 & 15 & 0.02 & 100 & 0.039 & 18 & 311 & \\
\hline 8 & 2704 & $5 / 41930$ & $5 / 51020$ & 0 & 0.3 & 8 & 15 & 0.02 & 100 & 0.048 & 18 & 331 & \\
\hline 9 & 2705 & $5 / 51600$ & $5 / 71254$ & 0 & 0.33 & 8 & 15 & 0.02 & 100 & 0.008 & 20 & 56 & \\
\hline 10 & 2706 & $5 / 41930$ & $5 / 5945$ & 0 & 0.25 & 8 & 15 & 0.02 & 100 & 0.066 & 18 & 546 & \\
\hline 11 & 2707 & $5 / 41930$ & $5 / 5955$ & 0 & 0.37 & 8 & 15 & 0.2 & 100 & 0.021 & 18 & 12 & \\
\hline 12 & 2707 & $5 / 41930$ & $5 / 51040$ & 0 & 0.37 & 8 & 15 & 0.2 & 100 & 0.021 & 18 & 12 & Duplicate analysis \\
\hline 13 & 2708 & $5 / 41930$ & $5 / 5935$ & 0 & 0.25 & 8 & 15 & 0.02 & 100 & 0.098 & 18 & 811 & \\
\hline 14 & 2709 & $5 / 41930$ & $5 / 5925$ & 0 & 0.25 & 8 & 15 & 0.02 & 100 & 0.116 & 18 & 960 & \\
\hline 15 & 2701-B & $5 / 51600$ & $5 / 62130$ & 0 & 0.22 & 8 & 15 & 0.02 & 100 & 0.011 & 20 & 115 & Duplicate digestion \\
\hline 16 & NIST2710 & $5 / 41930$ & $5 / 51000$ & 0 & 0.23 & 8 & 15 & 0.2 & 100 & 0.034 & 18 & 31 & $32.6 \pm 1.6$ \\
\hline 17 & NIST2710 & $5 / 41930$ & $5 / 71418$ & 0 & 0.23 & 8 & 15 & 0.2 & 100 & 0.034 & 19 & 32 & $32.6 \pm 1.6$ \\
\hline 18 & NIST2710 & $5 / 41930$ & $5 / 71426$ & 0 & 0.23 & 8 & 15 & 0.2 & 100 & 0.032 & 19 & 30 & $32.6 \pm 1.6$ \\
\hline 19 & NIST2710 & $5 / 41930$ & $5 / 5 \quad 1700$ & 0 & 0.23 & 8 & 15 & 0.2 & 100 & 0.035 & 18 & 32 & $32.6 \pm 1.6$ \\
\hline 20 & NIST8407 & $5 / 41930$ & $5 / 51010$ & 0 & 0.24 & 8 & 15 & 0.2 & 100 & 0.051 & 18 & 44 & $50 \pm 2$ \\
\hline 21 & NIST8407 & $5 / 41930$ & $5 / 71422$ & 0 & 0.24 & 8 & 15 & 0.2 & 100 & 0.056 & 19 & 51 & $50 \pm 2$ \\
\hline 22 & NIST 8407 & $5 / 81312$ & $5 / 81340$ & 0 & 0.3 & 8 & 15 & 0.2 & 100 & 0.082 & 16 & 50 & $50 \pm 2$ \\
\hline
\end{tabular}

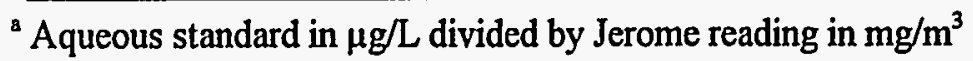

${ }^{\mathrm{b}}(((\mathrm{J} * \mathrm{~K} * \mathrm{I}) / \mathrm{H}) *(\mathrm{~F}+\mathrm{G})) /\left(\left(1-\mathrm{D}^{*} 0.01\right) * \mathrm{E}\right) * 0.001$ 


\subsection{Quality Control}

The Jerome mercury analyzer should be checked for proper operation and internal calibration before each use in accordance with the instruction manual provided by Arizona Instrument, Inc. Return of this analyzer to the factory for service and calibration at least annually is strongly recommended. The need for calibration is readily determined if a "Functional Test Kit" is purchased from the manufacturer. The Jerome may still be used for the method described here even if the internal calibration drifts out of specifications, but the instrument should be returned when it no longer indicates proper calibration. Use of an analyzer which lacks proper internal calibration must be accompanied by the external calibration described here and the analyzer must not be used further in the main application (industrial hygiene/protection of human health) for which it was designed.

Quality assurance of the results being generated by this method can be tracked by inclusion of NIST, or equivalent, reference soils with each batch of site soils, and by regularly verifying/adjusting the slope factor determined by external calibration with a low- or midrange aqueous standard. Experience has shown that at least one such aqueous standard run with each group of ten soil samples is sufficient. If significant drift is detected, standards should be run more frequently and the slope factor adjusted accordingly. Analysis of a continuing calibration blank and a soil extraction reagent blank should also be incorporated at a frequency of $10 \%$.

Replicate analyses of the same soil extract is a useful measure of method precision and should be performed at the rate of one per 20 soil samples. Replicate digests of the same soil are also useful but sample inhomogeneity can confound detection of the major source of poor precision. This is particularly true for soils analyzed in the naturally moist or wet state, or which contain visible elemental mercury. Such soils simply cannot be adequately homogenized for an analyzed aliquot size of a few hundred milligrams. True method precision is best established using NIST SRMs.

\subsection{Method Performance}

Three reference soil samples were used to evaluate the extraction efficiency of aqua regia under the conditions of this method. Two NIST Standard Reference/Research Materials, SRM 2710 (Montana soil, containing $32.6 \pm 1.8 \mu \mathrm{g} \mathrm{Hg} / \mathrm{g}$ ), RM 8407 (mercury in sediment, $50 \pm 2 \mu \mathrm{g}$ $\mathrm{Hg} / \mathrm{g}$ ), and a soil from the East Fork Poplar Creek (EFPC) floodplain (containing $2500 \mu \mathrm{g} \mathrm{Hg} / \mathrm{g}$ as measured by EPA Method 7471; EPA 1986), were weighed into clean Erlenmeyer flasks. These were extracted with $8 \mathrm{~mL}$ of aqua regia for $15 \mathrm{~min}$. The slurries were filtered, diluted with $175 \mathrm{~mL}$ of distilled deionized water, and $1 \mathrm{~mL}$ of concentrated $\mathrm{HNO}_{3}$ was added as a preservative. The extraction filtrates were submitted for laboratory analysis using EPA Method 245.1 (EPA 1982). The results (Table 1) indicated that digestion of soil in aqua regia at room temperature for 15 minutes adequately recovered mercury. Notably, the EFPC soil, which has been characterized (Revis et al 1989) as containing $85 \%$ mercuric sulfide, was extracted with high efficiency.

Numerous NIST reference/research soils have been analyzed during the development and testing of this method. Table 2 summarizes results for NIST soils analyzed by this method. In addition, several suites of soil or sediment samples for which mercury results were available by approved EPA protocols (Methods 7471/245.5) have also been run by this field method for comparative purposes. In most cases analyzed samples were dried and pulverized prior to analysis by both the field and laboratory protocols. In many cases, the aliquots for the field . 
method were taken from the same containers used to supply aliquots for the formal laboratory methods. Table 3 provides summary data for actual soils analyzed by both the field method described here and by the EPA-approved Method 7471 (EPA 1986). Figure 3 displays the results graphically.

Table 1. Extraction Efficiency of Aqua Regia at $22-24^{\circ} \mathrm{C}$ after 15-min Digestion.

\begin{tabular}{lccc} 
Sample & $\begin{array}{c}\text { Reference Value } \\
(\mu \mathrm{g} / \mathrm{g})\end{array}$ & $\begin{array}{c}\text { Observed Value } \\
(\mu \mathrm{g} / \mathrm{g})^{\mathbf{1}}\end{array}$ & $\begin{array}{c}\text { Average } \\
\text { \% Extracted }\end{array}$ \\
\hline NIST RM 8407 & $50 \pm 2$ & $50(14)^{2}$ & 100 \\
NIST SRM 2710 & $32.6 \pm 1.8$ & $31(7.8)$ & 96 \\
EFPC soil & 2500 & 2600 & 103 \\
\hline
\end{tabular}

${ }^{1}$ Average of duplicate (except EFPC soil) extracts analyzed using EPA Method 245.1 (EPA 1982).

${ }^{2}$ Values in ( ) are relative percent differences in duplicates 
Table 2. Results of Application of Field Method to NIST Reference/Research Materials

\begin{tabular}{|c|c|c|c|c|}
\hline NIST Soil ID & Date Analyzed & $\begin{array}{c}\text { Field } \\
\text { Mercury } \\
(\mu \mathrm{g} / \mathrm{g})\end{array}$ & $\begin{array}{c}\text { Certified } \\
\text { Mercury } \\
(\mu \mathrm{g} / \mathrm{g})\end{array}$ & $\begin{array}{c}\text { Percent } \\
\text { Difference }\end{array}$ \\
\hline RM 8407 & $12 / 14 / 94$ & 44 & $50 \pm 2$ & -12 \\
\hline RM 8407 & $12 / 14 / 94$ & 46 & $50 \pm 2$ & -8.0 \\
\hline SRM 2710 & $12 / 14 / 94$ & 30.4 & $32.6 \pm 1.8$ & -6.7 \\
\hline SRM 2710 & $12 / 14 / 94$ & 31.2 & $32.6 \pm 1.8$ & -4.2 \\
\hline SRM 2709 & $12 / 30 / 94$ & 1.88 & $1.40 \pm 0.08$ & 34 \\
\hline SRM 2709 & $2 / 8 / 95$ & 2.2 & $1.40 \pm 0.08$ & 57 \\
\hline SRM 2709 & $2 / 8 / 95$ & 3.4 & $1.40 \pm 0.08$ & 142 \\
\hline SRM 2710 & $2 / 8 / 95$ & 33 & $32.6 \pm 1.8$ & 1.2 \\
\hline RM 8407 & 2/8/95 & 39 & $50 \pm 2$ & -22 \\
\hline RM 8407 & $2 / 8 / 95$ & 45 & $50 \pm 2$ & -10 \\
\hline SRM 2710 & 2/9/95 & 33 & $32.6 \pm 1.8$ & 1.2 \\
\hline SRM 2710 & $2 / 9 / 95$ & 33 & $32.6 \pm 1.8$ & 1.2 \\
\hline SRM 2710 & $2 / 9 / 95$ & 36 & $32.6 \pm 1.8$ & 10 \\
\hline SRM 2710 & $2 / 10 / 95$ & 31 & $32.6 \pm 1.8$ & -5.0 \\
\hline SRM 2710 & $2 / 10 / 95$ & 29 & $32.6 \pm 1.8$ & -11 \\
\hline SRM 2711 & $2 / 10 / 95$ & 6.5 & $6.25 \pm 0.19$ & 4.0 \\
\hline SRM 2710 & $2 / 11 / 95$ & 36 & $32.6 \pm 1.8$ & 10 \\
\hline SRM 2711 & $2 / 11 / 95$ & 6.0 & $6.25 \pm 0.19$ & -4.0 \\
\hline SRM 2710 & $2 / 11 / 95$ & 31 & $32.6 \pm 1.8$ & -4.9 \\
\hline SRM 2710 & $2 / 11 / 95$ & 38 & $32.6 \pm 1.8$ & 16 \\
\hline SRM 2709 & $2 / 11 / 95$ & 2.4 & $1.40 \pm 0.08$ & 71 \\
\hline SRM 2709 & $2 / 11 / 95$ & 2.4 & $1.40 \pm 0.08$ & 71 \\
\hline RM 8407 & $2 / 11 / 95$ & 50 & $50 \pm 2$ & 0 \\
\hline SRM 2709 & $2 / 11 / 95$ & 1.9 & $1.40 \pm 0.08$ & 36 \\
\hline SRM 2710 & $2 / 11 / 95$ & 26 & $32.6 \pm 1.8$ & -20 \\
\hline RM 8407 & $2 / 11 / 95$ & 49 & $50 \pm 2$ & -2.0 \\
\hline SRM 2710 & $2 / 21 / 95$ & 32 & $32.6 \pm 1.8$ & -1.8 \\
\hline
\end{tabular}




\begin{tabular}{|c|c|c|c|c|}
\hline $0^{\circ} \leftarrow$ & $\tau \mp 0 S$ & $8 t$ & S6/8Z/9 & L0t8 Wy \\
\hline 0.0 & $\tau \mp 0 S$ & OS & S6/0E/9 & LOt8 NY \\
\hline $0^{\circ} 0$ & $\tau \mp 0 S$ & OS & S6/0E/9 & LO†8 N8 \\
\hline $0 \div$ & $\tau \mp 0 S$ & $Z S$ & $56 / 8 Z / 9$ & L0t8 Wd \\
\hline 0.8 & $\tau \mp 0 S$ & $t S$ & S6/8Z/9 & L0†8 WX \\
\hline $0 \%$ & $\tau \mp 0 S$ & $L t$ & S6/L/9 & LO†8 WX \\
\hline $0^{\circ} 9-$ & $\tau \mp$ os & $L t$ & $S 6 / L / 9$ & LOt8 WX \\
\hline 0.0 & $\tau \mp 0 S$ & $0 S$ & S6/L/9 & L0t8 Wd \\
\hline 0.5 & $\tau \mp$ OS & $2 S$ & $S 6 / L / 9$ & L0†8 Wy \\
\hline 0.0 & $\tau \mp 0 S$ & OS & S6/I/9 & LOt8 WX \\
\hline $0.8-$ & $8^{\circ} I \mp 9^{\circ} Z \varepsilon$ & $0 \mathcal{E}$ & $S 6 / I / 9$ & OILZ NAS \\
\hline $0 \bullet$ & $\tau \mp 0 S$ & $8 t$ & S6/IE/S & LOt8 WX \\
\hline $0.8-$ & $\tau \mp 0 S$ & $9 t$ & S6/IE/S & LOt8 WX \\
\hline $08-$ & $8^{\circ} I \mp 9^{\circ} 2 \varepsilon$ & $O E$ & S6/8Z/S & OILZ WYS \\
\hline $6^{\circ} t$ & $8^{\circ} \mathrm{I} \mp 9^{\circ} \mathrm{ZE}$ & IE & S6/8Z/S & OILZ WXS \\
\hline $0^{\circ} 0$ & $\tau \mp 0 S$ & OS & S6/わ/S & L0t8 WX \\
\hline ZI- & $\tau \mp 0 S$ & $t$ & $S 6 / t / S$ & LOt8 WY \\
\hline $8^{\circ} I^{-}$ & $8^{\circ}$ I $\mp 9^{\circ} 2 \varepsilon$ & $\tau \mathcal{E}$ & $S 6 / t / S$ & oTLZ WAS \\
\hline $0.8-$ & $8^{\circ} I \mp 9^{\circ} Z E$ & $O \mathcal{E}$ & $S 6 / t / S$ & OILZ WYS \\
\hline $8^{*} I-$ & $8^{\circ} I \mp 9^{\circ} Z \varepsilon$ & $\tau \mathcal{E}$ & $S 6 / t / S$ & OILZ WAS \\
\hline $6^{\circ} t$ & $8^{\circ} I \mp 9 \cdot 2 \varepsilon$ & IE & $S 6 / t / S$ & OILZ KAS \\
\hline 0.9 & $\tau \mp 0 S$ & $L t$ & S6/IZ/Z & LOt8 IN \\
\hline 0.9 & $\tau \mp 0 S$ & $\varepsilon S$ & S6/IZ/Z & L0†8 WX \\
\hline$\tau z-$ & $\tau \mp 0 S$ & $6 E$ & S6/IZ/Z & LOt8 Wd \\
\hline 0.0 & $\tau \mp 0 S$ & OS & $\$ 6 / I Z / Z$ & LOt8 WX \\
\hline 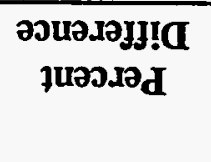 & 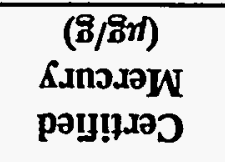 & 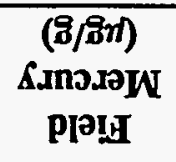 & pəzא[вuץ әұв & aI I!OS ISIN \\
\hline
\end{tabular}

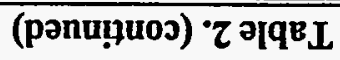


A-16

Table 3. EFPC Soils Analyzed by Both Field and Laboratory Methods

\begin{tabular}{|c|c|c|c|c|}
\hline Sample ID & Date Analyzed & $\begin{array}{c}\text { Field } \\
\text { Mercury } \\
(\mu \mathrm{g} / \mathrm{g})\end{array}$ & $\begin{array}{c}\text { Laboratory } \\
\text { Mercury } \\
(\mu \mathrm{g} / \mathrm{g})\end{array}$ & $\%$ Difference $^{\mathrm{a}}$ \\
\hline ZE5150717 & $12 / 14 / 94$ & 213 & 230 & -7.42 \\
\hline ZE3181013 & $12 / 14 / 94$ & 27 & 28 & -5.36 \\
\hline ZE3740918 & $12 / 14 / 94$ & 53 & 55 & -3.32 \\
\hline ZE5380512 & $12 / 14 / 94$ & 66 & 67 & -1.77 \\
\hline ZE5150717 & $12 / 14 / 94$ & 211 & 230 & -8.21 \\
\hline ZE5470412 & $12 / 14 / 94$ & 78 & 85 & -8.01 \\
\hline ZN3210115 & $12 / 14 / 94$ & 241 & 260 & -7.38 \\
\hline ZN3340211 & $12 / 14 / 94$ & 285 & 270 & 5.41 \\
\hline ZN3210127 & $12 / 14 / 94$ & 2471 & 2630 & -6.06 \\
\hline ZE5380524 & $12 / 14 / 94$ & 1720 & 2100 & -18.09 \\
\hline ZE3770822 & $12 / 15 / 94$ & 24 & 15.3 & 56.91 \\
\hline ZE3740920 & $12 / 15 / 94$ & 442 & 780 & -43.28 \\
\hline ZE3181025 & $12 / 15 / 94$ & 338 & 390 & -13.38 \\
\hline ZE3770810 & $12 / 15 / 94$ & 366 & 480 & -23.75 \\
\hline ZE5150729 & $12 / 15 / 94$ & 942 & 900 & 4.62 \\
\hline ZE5340621 & $12 / 15 / 94$ & 1038 & 1200 & -13.54 \\
\hline ZE5670424 & $12 / 15 / 94$ & 1282 & 1300 & -1.41 \\
\hline ZN3210127 & $12 / 15 / 94$ & 2633 & 2630 & 0.12 \\
\hline ZN3340223 & $12 / 15 / 94$ & 1721 & 1900 & -9.40 \\
\hline $\mathrm{ZN} 3340324$ & $12 / 15 / 94$ & 1818 & 2100 & -13.43 \\
\hline ZN3340324 & $12 / 15 / 94$ & 1852 & 2100 & -11.79 \\
\hline ZE3740920 & $12 / 15 / 94$ & 554 & 780 & -29.02 \\
\hline $\mathrm{BA1}$ & $2 / 21 / 95$ & 2500 & 2500 & 0.00 \\
\hline $\mathrm{BA2}$ & $2 / 21 / 95$ & 620 & 570 & 8.77 \\
\hline BA3 & $2 / 21 / 95$ & 920 & 790 & 16.46 \\
\hline BA4 & $2 / 21 / 95$ & 200 & 220 & -9.09 \\
\hline BA5 & $2 / 21 / 95$ & 510 & 550 & -7.27 \\
\hline BA6 & $2 / 21 / 95$ & 1300 & 1300 & 0.00 \\
\hline BA7 & $2 / 21 / 95$ & 1800 & 1800 & 0.00 \\
\hline $\mathrm{BA} 8$ & $2 / 21 / 95$ & 250 & 250 & 0.00 \\
\hline $\mathrm{BA9}$ & $2 / 21 / 95$ & 550 & 520 & 5.77 \\
\hline BA10 & $2 / 21 / 95$ & 1000 & 980 & 2.04 \\
\hline
\end{tabular}

a 100 x ((Field - Lab)/Lab) 


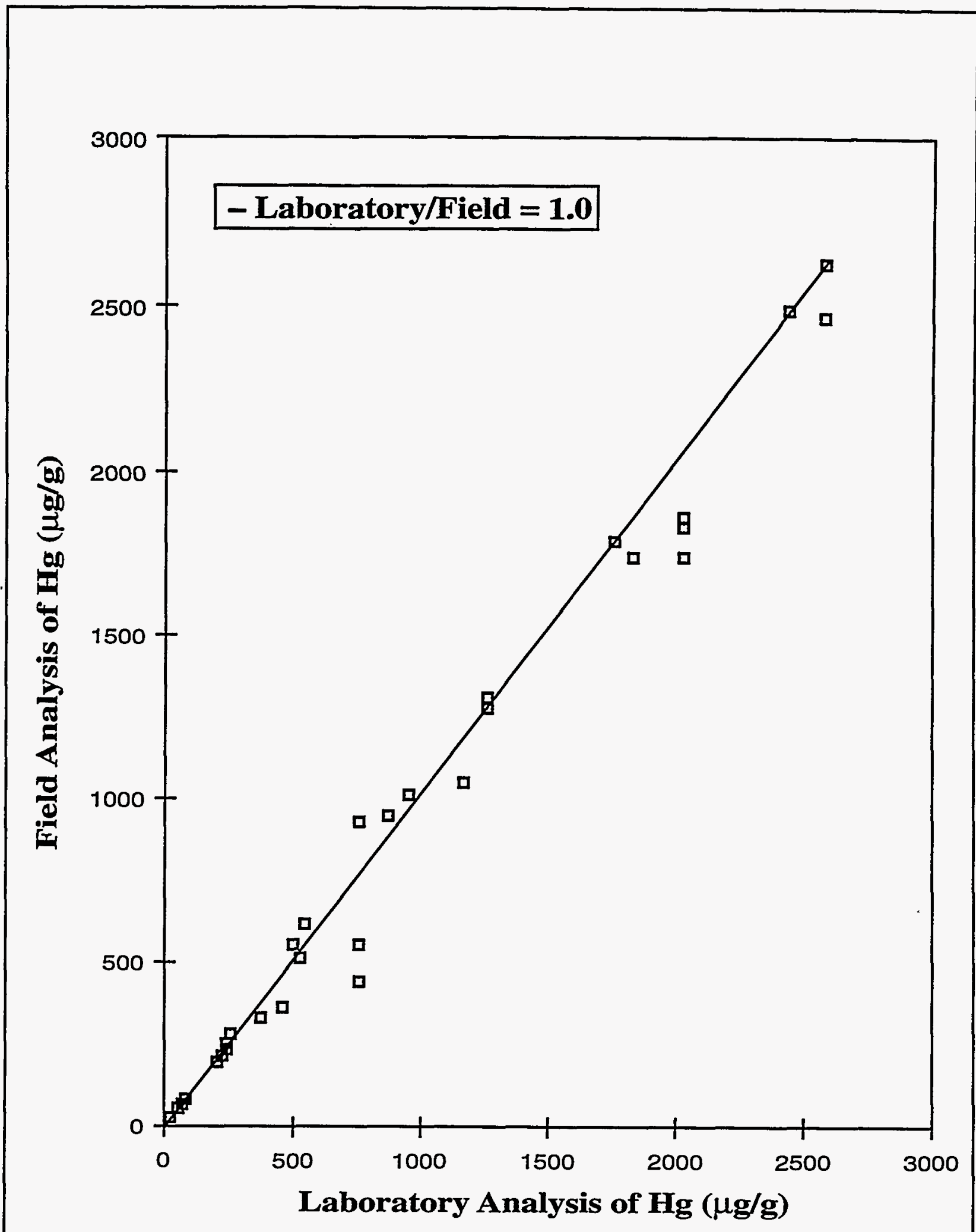

Figure 3. Intercomparison of Results for EFPC Soils Analyzed $24-032996-027 b$ by Both Field and Laboratory Methods 


\subsection{References}

Environmental Protection Agency (EPA): 1982, Methods for Chemical Analysis of Water and Wastes. EPA-600/4-82-55.

Environmental Protection Agency (EPA): 1986, Test Methods for Evaluating Solid Waste, Third Edition. SW-846.

Revis, N.W., Osborne, T.R., Holdsworth, G., Hadden, C.: 1989, Water, Air and Soil Pollution. 45, 105-113.

Kriger, A.A., Turner, R.R.: 1995, Water, Air and Soil Pollution. 80, 12951304. 


\section{DISTRIBUTION}

1. L. V. Asplund

2-3. A. K. Lee/DOE-OSTI

4-6. D. M. Matteo

7-8. T. J. McLaughlin

9. L. W. McMahon

10. H. C. Newsom

11. P. T. Owen

12. S. A. White

13. R. W. Weigel

14. ER Document Management Center-RC

15-16. R. C. Sleeman, Director, Environmental Restoration Division, DOE Oak Ridge Operations Office, P.O. Box 2001, Oak Ridge, TN 37831-8541

17. B. Issel, Community Development Director, City of Oak Ridge, P. O. Box 1, Oak Ridge, TN 37831-0001

18. H. L. Wieland, Black \& Veatch, 400 Northridge Road, Suite 350, Atlanta, GA 30350

19-21. R. Hedrick, U.S. Army Corps of Engineers, Nashville District, P.O. Box 1070, Nashville, TN 37902

22. R. M. Meccia, Foster Wheeler Environmental Corporation, 111 Union Valley Road, Oak Ridge, TN 378302

23-24 T. E. Myrick, Science Applications International Corporation, P.O. Box 2502, Oak Ridge, TN 37831

25. J. W. McCollum, MK-Ferguson of Oak Ridge Company, P.O. Box 2000, Oak Ridge, TN 37831 